\title{
Cellular and Molecular
} Underpinnings of Neuronal Assembly in the Central Auditory System during Mouse Development

\section{OPEN ACCESS}

Edited by:

Catherine Carr,

University of Maryland, College Park,

USA

Reviewed by:

Karina S. Cramer,

University of California, Irvine, USA

Daniel Llano,

University of Illinois at

Urbana-Champaign, USA

*Correspondence:

Michèle Studer

michele.studer@unice.fr

Received: 21 December 2016 Accepted: 01 March 2017 Published: 19 April 2017

Citation:

Di Bonito M and Studer M (2017) Cellular and Molecular Underpinnings of Neuronal Assembly in the Central Auditory System during Mouse

Development.

Front. Neural Circuits 11:18.

doi: 10.3389/fncir.2017.00018

\section{Maria Di Bonito and Michèle Studer* \\ Université Côte d'Azur, CNRS, Inserm, iBV, Nice, France}

During development, the organization of the auditory system into distinct functional subcircuits depends on the spatially and temporally ordered sequence of neuronal specification, differentiation, migration and connectivity. Regional patterning along the antero-posterior axis and neuronal subtype specification along the dorso-ventral axis intersect to determine proper neuronal fate and assembly of rhombomere-specific auditory subcircuits. By taking advantage of the increasing number of transgenic mouse lines, recent studies have expanded the knowledge of developmental mechanisms involved in the formation and refinement of the auditory system. Here, we summarize several findings dealing with the molecular and cellular mechanisms that underlie the assembly of central auditory subcircuits during mouse development, focusing primarily on the rhombomeric and dorso-ventral origin of auditory nuclei and their associated molecular genetic pathways.

Keywords: central auditory system, rhombomeres, DV molecular determinants, Hox genes, mouse lineage tracing

\section{INTRODUCTION}

Hearing depends on the transmission and transduction of sound stimuli in the inner ear and on processing sensory information in the central nervous system. Proper development and function of both peripheral and central components are necessary for normal sound perception. In this review, we will recapitulate the anatomical, molecular and functional mechanisms involved in the assembly of the central auditory system in the developing mouse. It is known that the unique molecular identity of each rhombomere along the antero-posterior (AP) and the shared genetic pathways of dorso-ventral (DV) domains confer a positional pattern on neuronal progenitors, determining their neuronal subtype identities, migratory pathways, and axonal projections to their proper targets. Several studies have started to correlate early rhombomeric territories and specific DV domains to adult auditory neuronal identity, migration and connectivity patterns (Farago et al., 2006; Louvi et al., 2007; Fujiyama et al., 2009; Maricich et al., 2009; Rose et al., 2009; Di Bonito et al., 2013a; Marrs et al., 2013; Altieri et al., 2015, 2016; Cai et al., 2016). Because of the complexity of the auditory system, the genetic and functional dissection of the different auditory subcircuits have allowed a better comprehension on how neuronal components contribute to distinct pathways with particular functions during development (Maricich et al., 2009; Di Bonito et al., 2013a; Jalabi et al., 2013; Altieri et al., 2014). The availability of Cre- and Flp-recombinase specific mouse lines coupled to reporter lines has become a key tool in labeling genetically defined cell populations and identifying the 
embryonic origin of auditory hindbrain nuclei. Conditional knock-in and knock-out transgenic mice have allowed testing the function of individual genes during the construction of the auditory system and the characterization of their pathological role during hearing loss or deafness. Dissecting the anatomical components and functional role of auditory circuits in both normal and pathological conditions contributes to decipher the complexity of sound encoding processes. Moreover, identifying novel genes and molecular pathways specific to distinct rhombomere-specific subcircuits of the developing auditory system is crucial in finding novel players involved in different patterning aspects of hindbrain circuit formation and in the identification of genetic mutations causative of human hearing loss disorders. Below, we will first describe our knowledge about early hindbrain patterning and general anatomy of the auditory system. Then, we will summarize the progress made in the characterization of the rhombomeric and DV origin of auditory hindbrain nuclei and in the identification of genes that along the $\mathrm{AP}$ and DV axes are involved in rhombomere-specific formation of distinct functional auditory subcircuits.

\section{PATTERNING THE HINDBRAIN: A SEGMENTATION PROCESS CRUCIAL FOR FUTURE CIRCUIT ORGANIZATION}

\section{Antero-Posterior Domains: Rhombomeres and Crypto-Rhombomeres}

The hindbrain is an embryonic transient structure, which is subdivided into overt rhombomeres ( $r$ ) and rhombomere-like hidden segments called pseudo- or crypto-rhombomeres along the AP axis, and which will give rise to the prepontine region including the cerebellum (isthmus or $\mathrm{r} 0, \mathrm{r} 1, \mathrm{r} 2$ ), the pons $(\mathrm{r} 3, \mathrm{r} 4)$, the retropontine region $(\mathrm{r} 5, \mathrm{r} 6)$, and the medulla oblongata (r7-r11) in the adult brain (Puelles, 2013; Puelles et al., 2013; Figure 1). Overt rhombomeres (r2-r6) can be distinguished morphologically in the developing fourth ventricle at early developmental stages, appearing as distinct bulges

\footnotetext{
Abbreviations: V, Trigeminal motor nucleus; VII, Facial motor nucleus; VIII, Vestibulocochlear nuclei; VIIIn, VIIIth cranial nerve; X, Dorsal vagal motor nucleus; XII, Hypoglossal motor nucleus; Amb, Ambiguus motor nucleus; AP, Area postrema; AVCN, Anteroventral cochlear nucleus; Cb, Cerebellum; CES, Cochlear extramural stream; CN, Cochlear Nucleus; Cx, Cerebral cortex; DAS, Dorsal acoustic stria; DCN, Dorsal cochlear nucleus; dcn, Dorsal column nuclei; DLL, Dorsal nucleus of the lateral lemniscus; ECn, External cuneate nucleus; FBM, Facial branchiomotor neuron; FL, Floor plate; GBC, Globular bushy cell; IAS, Intermediate acoustic stria; IC, Inferior colliculus; IHC, Inner hair cell; ILL, Intermediate nucleus of the lateral lemniscus; LOC, Lateral olivocochlear neurons; LNTB, Lateral nucleus of the trapezoid body; LRL, Lower rhombic lip; LSO, Lateral superior olive; MG, Medial geniculate nucleus; MOC, Medial olivocochlear neurons; MNs, Somatic motor neuron; mnsh, Microneuronal shell; MNTB, Medial nucleus of trapezoid body; MNv, Visceral motor neurons; MSO, Medial superior olive; MZ, Mantle zone; NC, Notochord; OHC, Outer hair cell; PrV, Principal trigeminal nucleus; PVCN, Posteroventral cochlear nucleus; RAmb, Retroambiguus nucleus; RP, Roof plate; SBC, Spherical bushy cell; SC, Spinal cord; SG, Spiral ganglion; TBM, Trigeminal branchiomotor neuron; SOC, Superior olivary complex; SPO, Superior paraolivary nucleus; TB, Trapezoid body; VCN, Ventral cochlear nucleus; VLL, Ventral nucleus of the lateral lemniscus; VNTB, Ventral nucleus of the trapezoid body; VZ, Ventricular zone.
}

along the neural tube wall separated by external transverse constrictions and ventricular inter-rhombomeric ridges (Vaage, 1969; Lumsden, 1990). Rhombomeres consists of true segmental compartments displaying typical cellular and molecular characteristics, such as clonal lineage restriction (Fraser et al., 1990; Jimenez-Guri et al., 2010), whereas rhombomeric boundaries have reduced gap-junctional permeability (Martinez et al., 1992), specific cell cycle kinetics (Guthrie et al., 1991) and expression of distinct molecular markers (Heyman et al., 1995). More rostrally, patterning of the isthmus (r0), as well as $\mathrm{r} 1$, is not governed by intersegmental boundaries but develop under the influence of gradient signals from the isthmic organizer, forming a morphogenetic field together with the caudal midbrain (Martinez, 2001). The isthmus can be distinguished from $\mathrm{r} 1$ only thanks to molecular markers (Aroca and Puelles, 2005; Puelles, 2013). Caudally to r6, the hindbrain appears as an apparently non-segmented region and lacks visible intersegmental boundaries. However, even if transverse constrictions are not distinguishable as in overt rhombomeres, quail-to-chick graft experiments, analysis of Hox gene expression domains and cytoarchitectonic landmarks in chicken and mouse medulla oblongata have revealed a hidden transverse organization of the caudal hindbrain, corresponding to a subdivision into five compartments ( $r 7-\mathrm{r} 11)$, named cryptorhombomeres (Cambronero and Puelles, 2000; Marin et al., 2008; Tomas-Roca et al., 2016; Figure 1).

The homeotic Hox genes are the earliest genes that delimit rhombomeric boundaries along the AP hindbrain axis. Indeed, the overt inter-rhombomeric boundaries of $\mathrm{r} 1 / \mathrm{r} 2$ to $\mathrm{r} 6 / \mathrm{r} 7$ correlate with the anterior boundary of Paralog Groups (PG) 13 Hox genes following the principle of $3^{\prime}-5^{\prime}$ spatial collinearity (Krumlauf et al., 1993; Parrish et al., 2009; Tumpel et al., 2009). Similarly, the experimentally fate-mapped boundaries of r7-r11 coincide with the rostral expression limits of PG 47 Hox genes (Marin et al., 2008; Tomas-Roca et al., 2016). Each of these rhombomeres and crypto-rhombomeres, except $\mathrm{r} 1$, expresses a particular combination of Hox genes, which specify their molecular identity and developmental fate. Both overt and cryptic rhombomere-derived territories persist until adult stages, as demonstrated by quail-chick grafting experiments (Marin and Puelles, 1995; Wingate and Lumsden, 1996; Cambronero and Puelles, 2000) and mouse rhombomere-specific transgenic fate mapping (Farago et al., 2006; Oury et al., 2006; Pasqualetti et al., 2007; Di Bonito et al., 2013a, 2015; Di Meglio et al., 2013; Tomas-Roca et al., 2016). The subdivision of the hindbrain into rhombomeres is highly conserved in vertebrates and is fundamental for the establishment of a complex network of circuits and subcircuits in the adult hindbrain.

Differently from the early rhombomeric organization, the mature hindbrain is organized into longitudinal columns of sensory and motor nuclei ranging from alar to basal and subdivided into discrete segmental units. The columns have a plurisegmental origin, and the molecular boundaries of overt and cryptic rhombomeres correlate topographically with the transverse limits of nuclei or intranuclear subdivisions (Marin and Puelles, 1995; Cambronero and Puelles, 2000; Marin et al., 2008; Tomas-Roca et al., 2016). Moreover, some nuclei display 


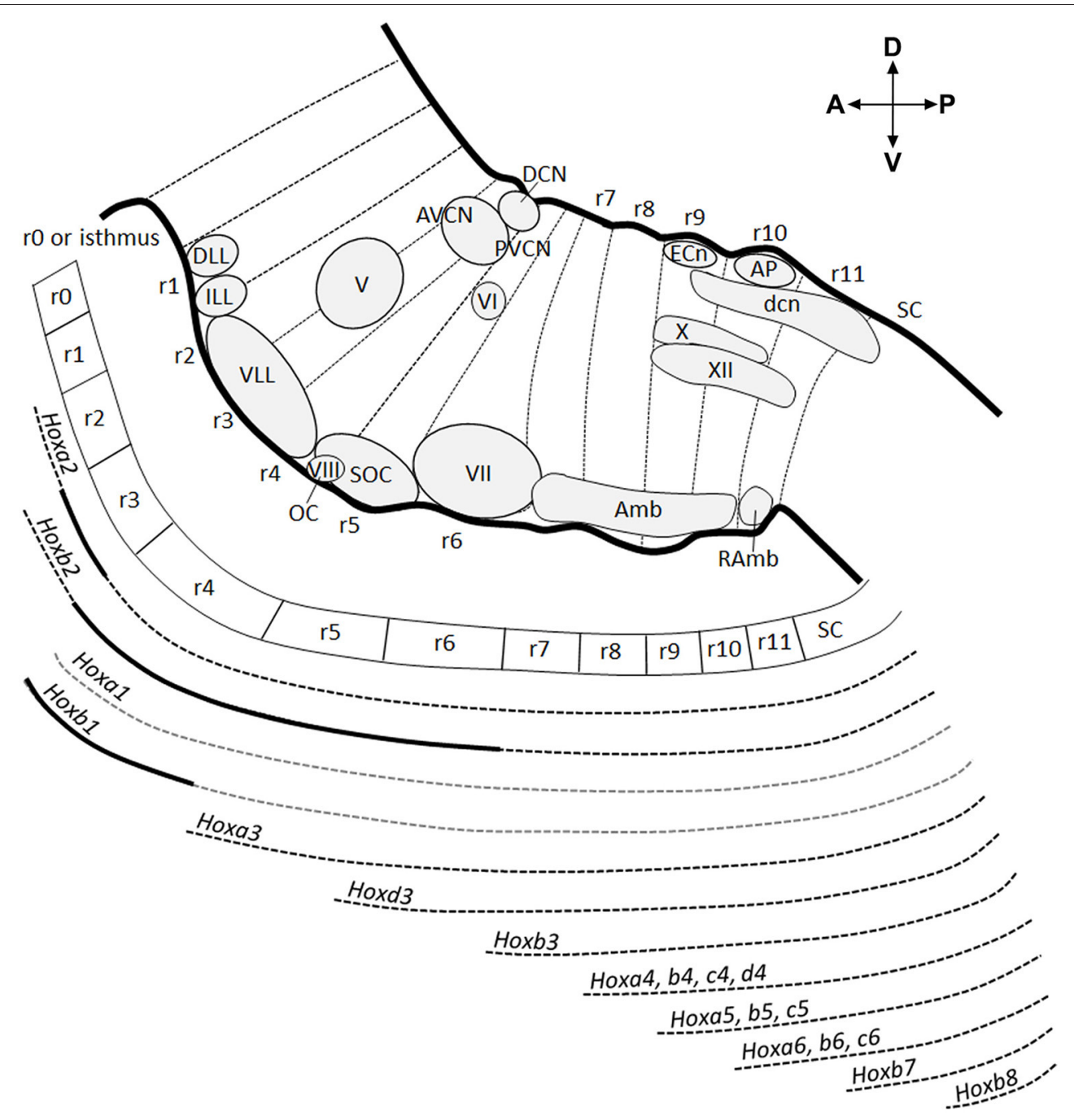

FIGURE 1 | Antero-posterior anatomical subdivision of the pons and medulla oblongata and corresponding Hox gene expression. Schema showing a sagittal view of the hindbrain subdivided into 12 transverse segments: isthmus and r1 (ro-r1) territories, 5 overt rhombomeres (r2-r6), and 5 crypto-rhombomeres (r7-r11) along the AP axis (above). Below, corresponding Hox expression profile correlated to the intersegmentary boundaries and transverse limits of nuclei or intranuclear division. Gray dotted lines refer to Hoxa1 and Hoxb1 downregulation during early development. Thick black lines indicate upregulated expression of Hoxa2 in r3, Hoxb1 in r4 until E12.5 and Hoxb2 in r4-r6. Modified from Tomas-Roca et al. (2016).

an AP molecular regionalization according to the co-linear differential expression of Hox genes (Marin et al., 2008; TomasRoca et al., 2016; Figure 1). The original Hox code of each intracolumnar subdivision (jointly with other transcription factors) will then determine the ulterior development of specific neuronal identities and the overall heterogeneity of neuronal populations along the AP axis within sensorimotor columns (see more below).

\section{Dorso-Ventral Domains: Establishment of Neuronal Subpopulations}

Following the AP rhombomeric divisions, distinct neuronal subtypes arise at stereotyped positions along the DV axis in the developing hindbrain and spinal cord (Figure 2A). The generation of distinct progenitors at defined DV positions in the neural tube depends on two opposite morphogen gradients that act on neuroepithelial cells occupying the ventricular zone of the neural tube: a Sonic hedgehog (Shh) gradient (ventralizing signal) produced by the notochord and the floor plate, and Bone Morphogenetic Protein (BMP) and Wnt gradients (dorsalizing signals) produced by the overlying ectoderm and roof plate (Jessell, 2000; Ribes and Briscoe, 2009; Ulloa and Marti, 2010; Figure 2B). The ventralizing and dorsalizing inductive signals control, in a concentration-dependent manner, the expression of distinct homeodomain (HD) and basic-helix-loop-helix (bHLH) proteins along the DV axis and thus establish progenitor cell domains. Cross-repressive interactions between transcription factors in adjacent domains define sharp boundaries of progenitor domains preventing cells with hybrid identities. Each domain expresses a unique combination of transcription factors 


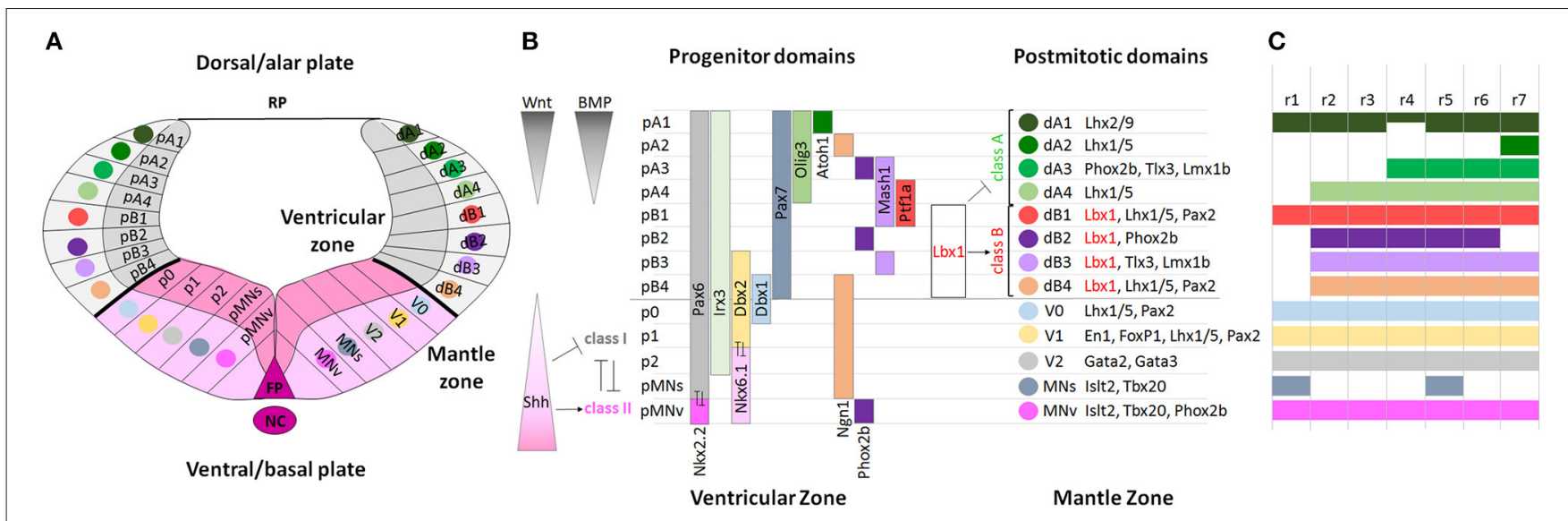

FIGURE 2 | Molecular specification of dorso-ventral neuronal cell fate in the hindbrain. (A) Schematic diagram showing the DV organization of a rhombomere from dorsal to ventral: roof plate (RP), dorsal (alar) and ventral (basal) subdomains, floor plate (FP) and notochord (NC). Each domain is formed by progenitors in the ventricular zone and by postmitotic neurons in the mantle zone. (B) Two opposite morphogen gradients of Wnt and BMP (dorsalizing signals) produced by the overlying ectoderm and roof plate, and Shh (ventralizing signal) produced by the notochord and floor plate control the expression of bHLH and HD proteins along the DV axis establishing distinct progenitor domains and directing the differentiation of neuronal subtypes. In the alar plate, dA1-dB4 classes of dorsal neurons are subdivided into class A and class B neurons, respectively repressed or activated by Lbx1 (in red). In the basal plate, HD class I genes are repressed and HD class II genes are activated by Shh signaling, and cross-repressive interactions between class I and class II proteins refine and maintain progenitor domains and determine interneuron (VO-V2), somatic (MNs), and visceral (MNv) motor neuron differentiation. Modified from Takahashi and Osumi (2002), Melton et al. (2004), and Storm et al. (2009). (C) Rhombomeric mapping of hindbrain DV domains, modified from Gray (2008). The DV domains extend differently across rhombomeres along the AP axis.

that defines the identity of neuronal progenitors, which in turn will give rise to postmitotic neuronal populations expressing specific neuronal-subtype-determining genes (Briscoe et al., 2000; Muller et al., 2002; Takahashi and Osumi, 2002; Lebel et al., 2007; Sieber et al., 2007; Storm et al., 2009; Alaynick et al., 2011). However, the DV domains are differentially represented along the $\mathrm{AP}$ axis resulting in some domains, which are reduced or even absent in specific rhombomeres (Figure 2C).

Interactions between the unique molecular identity of each rhombomere and the shared genetic mechanisms of DV patterning will lead to functionally-characteristic alar and basal derivatives of rhombomeres and crypto-rhombomeres, so that rhombomere-specific DV neuronal populations will partially contribute to pluri-neuromeric columnar arrangements (e.g., sensory cochlear, vestibular and trigeminal, as well as motor columns). Inductive signals and specific transcriptional pathways confer a positional identity on neural progenitors, in accordance with their position along the AP and DV axes, and determine the future neuronal fate of distinct neuronal subtypes, specific migratory pathways and axon projections to their corresponding targets (Gaufo et al., 2000, 2004; Pattyn et al., 2003a; Samad et al., 2004; Farago et al., 2006; Jacob et al., 2007; Sieber et al., 2007; Maricich et al., 2009; Storm et al., 2009; Di Bonito et al., 2013a). The regional patterning along the AP axis and neuronal subtype specification along the DV axis intersect and confer distinct rhombomere-specific subcircuits contributing to the complexity of hindbrain sensorimotor systems (Philippidou and Dasen, 2013; Di Bonito et al., 2013b). Long-term fate mapping studies of rhombomeres in chick (Marin and Puelles, 1995; Diaz et al., 1998; Cambronero and Puelles, 2000; Cramer et al., 2000; Marin et al., 2008) and mouse (Farago et al., 2006; Oury et al., 2006; Pasqualetti et al., 2007; Maricich et al., 2009; Rose et al., 2009;
Di Bonito et al., 2013a, 2015; Di Meglio et al., 2013; Gray, 2013; Tomas-Roca et al., 2016) have revealed that rhombomeres and crypto-rhombomeres give rise to sensory and motor nuclei of the auditory, vestibular, trigeminal, somatosensory and reticular systems. Single rhombomeres can contribute to nuclei belonging to distinct sensorimotor systems and multiple rhombomeres can contribute to distinct subdivisions of the same nucleus. Hindbrain nuclei relay sensorial information from the periphery to higher brains centers and descending motor information through interconnected neuronal circuits regulating several vital functions. In this review, we will focus on the processes involved in patterning the mouse auditory system and on the associated network of regulatory genes underlying these events.

\section{GENERAL FUNCTION AND ORGANIZATION OF THE SENSORIMOTOR AUDITORY SYSTEM}

Sound consists of alternating compressions and rarefactions propagating through the air. The auricle or pinna captures and conveys sounds to the middle ear, where mechanical energy is transmitted as motions of a chain of three small ossicles: the malleus, the incus and the stapes. Sound-induced mechanical vibrations of the middle ear are transmitted to the cochlea, the sensory end-organ for sound perception in the inner ear, generating in this way cochlear fluid movements. Deflection of the basilar membrane activates the sensory cells that transduce the mechanical energy of sound into electrical signals (Willott, 2001). To receive and elaborate these signals, the cochlea comprises two types of receptors, the inner and outer hair cells. The inner hair cells (IHCs) are the true detectors of auditory 
stimuli, while the outer hair cells (OHCs) are the amplifiers that enhance low-level sounds by increasing the amplitude and frequency selectivity of basilar membrane vibrations thanks to the "cochlear amplification" process (Ashmore et al., 2010; Guinan, 2013; Goutman et al., 2015). Auditory information is then transferred via the vestibulocochlear (VIIIth) cranial nerve to the brainstem, where auditory nuclei transmit ascending acoustic information, and efferent motor neurons modulate primary afferent responses. In particular, stimuli are first transmitted from IHCs through the primary afferent neurons of the VIIIth nerve to the cochlear nuclear (CN) complex, which is the primary relay station of the central auditory system. The auditory signals travel then from the $\mathrm{CN}$ through the main auditory pathway of sound perception consisting of the lateral lemniscus (LL) complex, the inferior colliculus (IC) in the midbrain, the medial geniculate nucleus (MG) in the thalamus, to finally reach the auditory cortex (Willott,
2001; Figure 3A). In a distinct and parallel pathway, excitatory and inhibitory inputs from the $\mathrm{CN}$ are first integrated and elaborated by the superior olivary complex (SOC) before being transmitted to higher auditory structures (Grothe et al., 2010; Figure 3A). This pathway is crucial for correct spatial sound localization.

Proper hearing function is also controlled by efferent motor neurons, which modulate afferent sensory auditory stimuli. The olivocochlear neurons (OC) are an important efferent component of the auditory system. In particular, lateral OC (LOC) motor neurons innervate afferent sensory neurons in synaptic contact with the IHCs, modulate cochlear nerve excitability and protect the cochlea from acoustic injury (Simmons, 2002; Darrow et al., 2007), whereas medial OC (MOC) motor neurons are innervated by neurons of the posterior ventral cochlear nucleus (PVCN) (Brown et al., 2003; de Venecia et al., 2005; Darrow et al., 2012) and inhibit

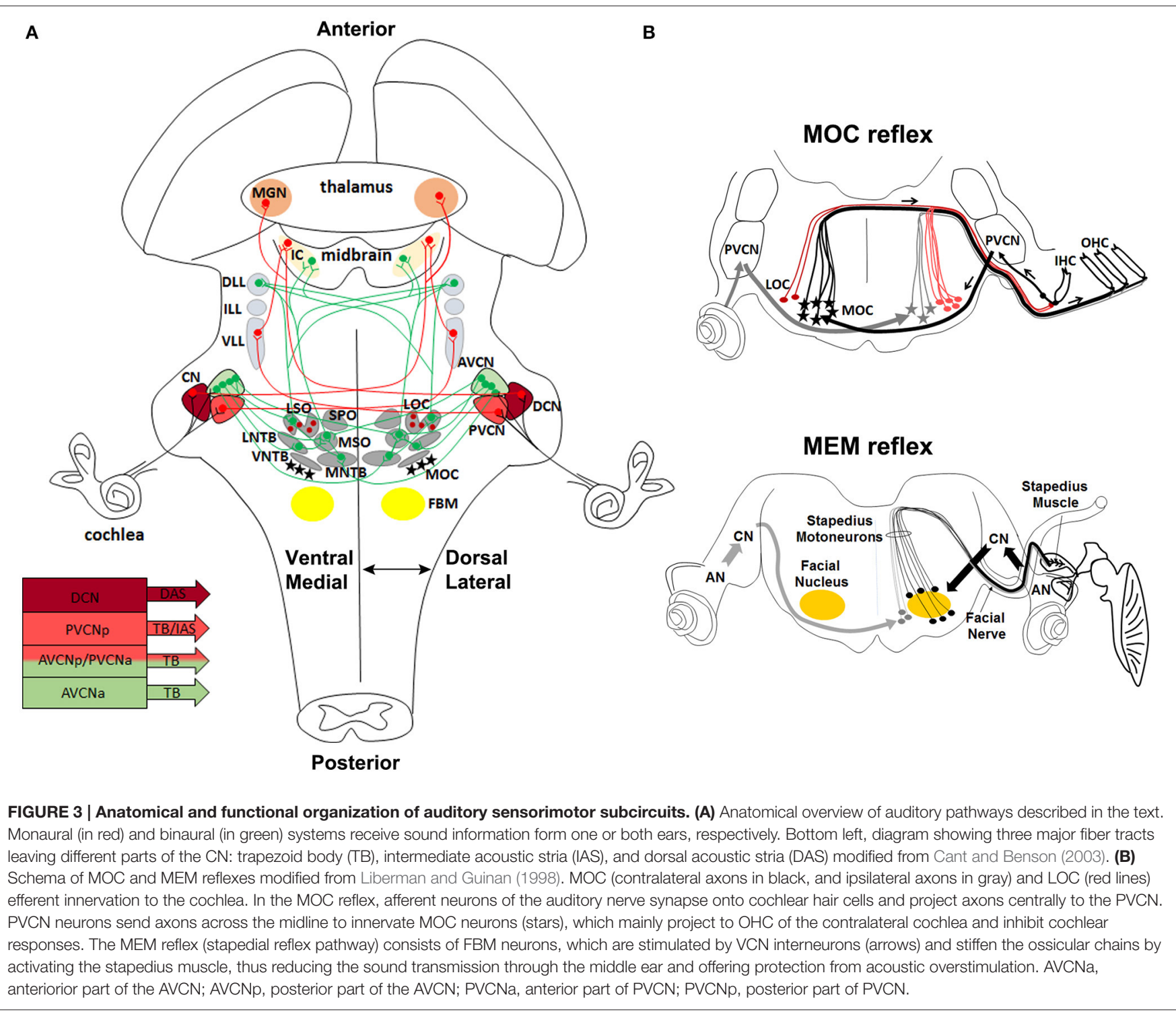


vibrating $\mathrm{OHCs}$ in the cochlea, thus modulating the sound amplification process through the MOC reflex (Wersinger and Fuchs, 2011) (Figure 3B). Moreover, interactions between cochlear efferent motor neurons and their postsynaptic targets are required for normal development of cochlear function during early postnatal stages (Walsh et al., 1998; Simmons, 2002; Di Bonito et al., 2013a). The middle-ear muscle reflex (MEM) is instead formed by facial and trigeminal branchiomotor neurons (FBM, TBM) that innervate the stapedius and tensor tympani muscles, respectively. The activation of these muscles tense the chain of tympanic ossicles and reduce the amplitude of sound transmission through the middle ear (Liberman and Guinan, 1998; Lee et al., 2006; Figure 3B). Thus, both the MOC and MEM reflexes represent two parallel soundevoked feedback mechanisms acting, respectively, on the inner and middle ear to modulate incoming acoustic stimuli (Kujawa and Liberman, 1997; Maison et al., 2002; Lee et al., 2006).

\section{ORIGINS OF DIFFERENT COMPONENTS OF THE CENTRAL AUDITORY SYSTEM}

In this section, we will discuss the evidence regarding the origin of sensory and motor auditory nuclei from distinct rhombomeres along the AP axis (Figure 4) and different domains along the DV axis (Figure 5), and summarize the role of transcription factors expressed in DV domains and required in the specification of distinct auditory neuronal subpopulations.

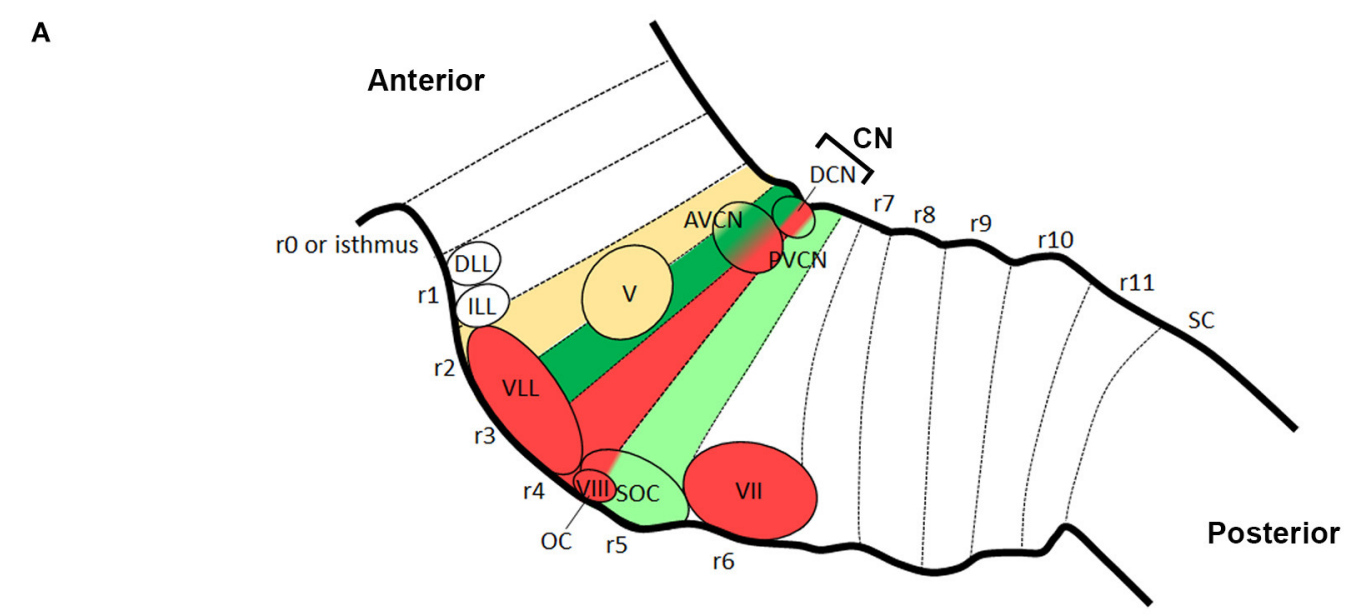

B

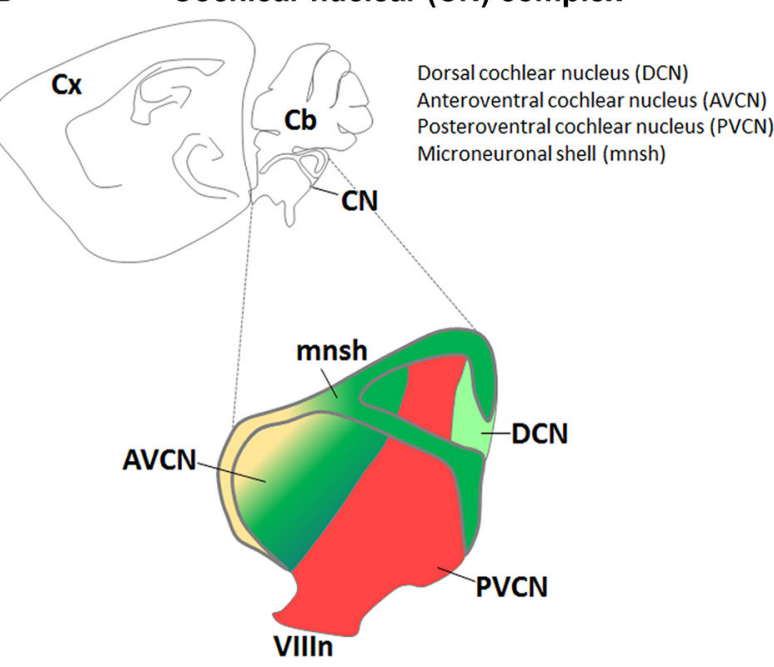

C Superior olivary complex (SOC)

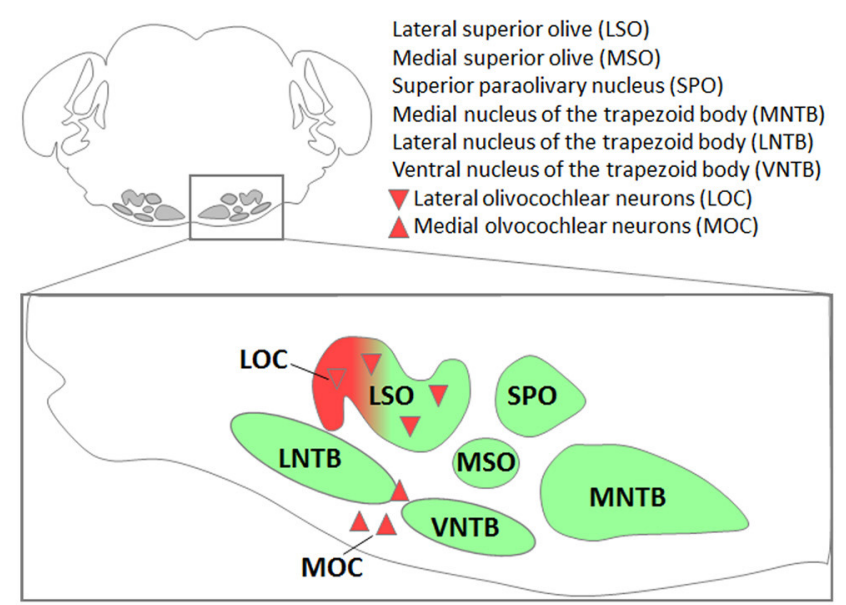

FIGURE 4 | Antero-posterior origin of auditory nuclei. (A) Schema showing a sagittal view of the hindbrain in which the color code represents rhombomeric origin of r2- (yellow), r3- (dark green), r4- (red), r5- (light green) derived territories and auditory nuclei. (B,C) Schematic representations of the (B) cochlear nuclear complex (AVCN, PVCN, DCN, and microneuronal shell), and (C) superior olivary complex (LSO, MSO, MNTB, VNTB, LNTB, SPO) and olivocochlear (LOC and MOC) neurons. Colors refer to their rhombomeric origin as described in (A). 


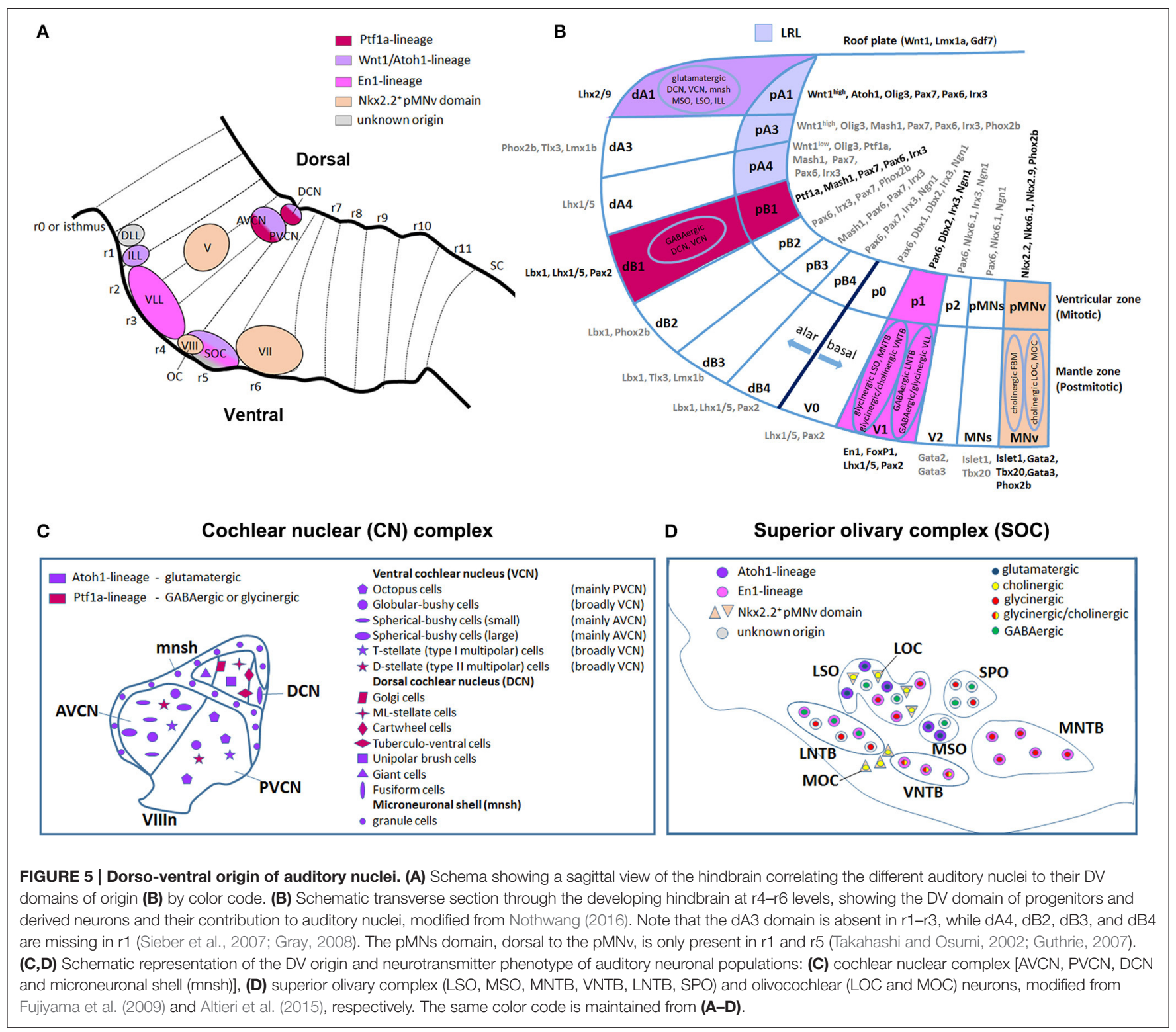

\section{The Cochlear Nuclear Complex as the Primary Relay Station of the Auditory System}

The cochlear nuclear $(\mathrm{CN})$ complex is subdivided into ventral (VCN) and dorsal (DCN) cochlear nuclei. While the DCN exhibits a laminar structure that contains the molecular (ML), the fusiform cell (FCL) and the deep (DL) layers, the VCN is further subdivided into anterior (AVCN) and posterior (PVCN) regions (Malmierca and Merchán, 2004; Oertel and Young, 2004; Figures 4A,B, Table 1). The CN is formed by a variety of neuronal subtypes that have different morphological, electrophysiological (e.g., inhibitory or excitatory) and molecular characteristics with unique projection patterns and distinct functional roles during sound processing. The DCN includes Golgi, ML-stellate, cartwheel, tuberculo-ventral, unipolar brush, giant and fusiform cells localized in one or multiple layers, whereas the VCN is formed by octopus, globular bushy, spherical bushy, T-stellate (type I multipolar) and D-stellate (type II multipolar) cells. Neuronal projections leave different parts of the $\mathrm{CN}$ via three major tracts, the ventral acoustic stria or trapezoid body (TB), the intermediate and dorsal acoustic stria, and target distinct brainstem nuclei (Cant and Benson, 2003). In particular, axons from the AVCN and the anterior part of PVCN leave the $\mathrm{CN}$ via the $\mathrm{TB}$, whereas axons from the posterior part of the PVCN project via the intermediate acoustic stria and those from the DCN via the dorsal acoustic stria (Figure 3A).

The cochlear complex originates from distinct regions of the r2-r5 neuroepithelium, which will give rise to the magnocellular cores of AVCN, PVCN and DCN cochlear nuclei, as well as to the cochlear granule cells of the microneuronal shell (mnsh) (Farago et al., 2006; Di Bonito et al., 2013a; Figures 4A,B, 
TABLE 1 | Summary of antero-posterior and dorso-ventral origin of auditory nuclei.

References

\begin{tabular}{|c|c|c|c|c|c|}
\hline $\begin{array}{l}\text { Auditory } \\
\text { nuclei }\end{array}$ & AP origin & $\begin{array}{l}\text { DV } \\
\text { origin }\end{array}$ & Geneteic lineage & $\begin{array}{l}\text { Neurotrasmitter } \\
\text { markers }\end{array}$ & Genetic markers (cell type) \\
\hline \multicolumn{6}{|c|}{ COCHLEAR NUCLEUS } \\
\hline AVCN & $\begin{array}{l}\text { r2-r3 (r4 } \\
\text { modestly) }\end{array}$ & $\begin{array}{l}\mathrm{pA} 1 \\
\mathrm{pB} 1\end{array}$ & $\begin{array}{l}\text { Atoh1/Wnt1/Wnt3a } \\
\text { Ptf1a }\end{array}$ & $\begin{array}{l}\text { VGluT1, VGluT2 } \\
\text { Gad67, VIAAT }\end{array}$ & $\begin{array}{l}\text { Lhx2, MafB } \\
\text { Atoh7/Parvalbumin (spherical bushy cells) } \\
\text { Atoh7/Calretinin (globular bushy cells) }\end{array}$ \\
\hline PVCN & $\begin{array}{l}\text { r4 (r3 } \\
\text { modestly) }\end{array}$ & $\begin{array}{l}\mathrm{pA} 1 \\
\mathrm{pB} 1\end{array}$ & $\begin{array}{l}\text { Atoh1Wnt1/Wnt3a } \\
\text { Ptf1a }\end{array}$ & $\begin{array}{l}\text { VGluT1, VGluT2 } \\
\text { Gad67,VIAAT }\end{array}$ & $\begin{array}{l}\text { Lhx2, MafB } \\
\text { Atoh7/Calretinin (globular bushy cells) } \\
\text { Calbindin (octopus cells) }\end{array}$ \\
\hline $\mathrm{DCN}$ & $r 3-r 4-r 5$ & $\begin{array}{l}\mathrm{pA} 1 \\
\mathrm{pB} 1\end{array}$ & $\begin{array}{l}\text { Atoh1/Wnt1/Wnt3a } \\
\text { Ptf1a }\end{array}$ & $\begin{array}{l}\text { VGluT2, VGluT3 } \\
\text { GABA, glycine, } \\
\text { Gad67, VIAAT }\end{array}$ & $\begin{array}{l}\text { Lhx2, Lhx9 } \\
\text { Bhlhb5/Pax2/Parvalbumin/CaMKIla } \\
\text { (cartwheel cells) } \\
\text { Bhlhb5/Pax6/Tbr2 (unipolar brush cells) } \\
\text { Grin2a (giant cells) } \\
\text { Grin2b (fusiform cells) } \\
\text { Parvalbumin (ML-stellate cells) }\end{array}$ \\
\hline mnsh & $r 2-r 3$ & pA1 & Atoh1/Wnt1 & VGluT1 & Barhl1, Pax6 \\
\hline
\end{tabular}

Wang et al., 2005; Farago et al., 2006;

Nichols and Bruce, 2006; Louvi et al., 2007; Yamada et al., 2007; Saul et al., 2008; Fujiyama et al., 2009; Maricich et al., 2009; Rose et al., 2009; Ito et al., 2011; Di Bonito et al., 2013a

Wang et al., 2005; Farago et al., 2006; Nichols and Bruce, 2006; Louvi et al., 2007; Yamada et al., 2007; Fujiyama et al., 2009; Maricich et al., 2009; Rose et al., 2009; Ito et al., 2011; Di Bonito et al., 2013a

Wang et al., 2005; Farago et al., 2006; Nichols and Bruce, 2006; Louvi et al., 2007; Yamada et al., 2007; Fujiyama et al., 2009; Maricich et al., 2009; Rose et al., 2009; Ito et al., 2011; Di Bonito et al., 2013a; Cai et al., 2016

Wang et al., 2005; Farago et al., 2006; Nichols and Bruce, 2006; Fujiyama et al., 2009; Ito et al., 2011; Di Bonito et al., 2013a

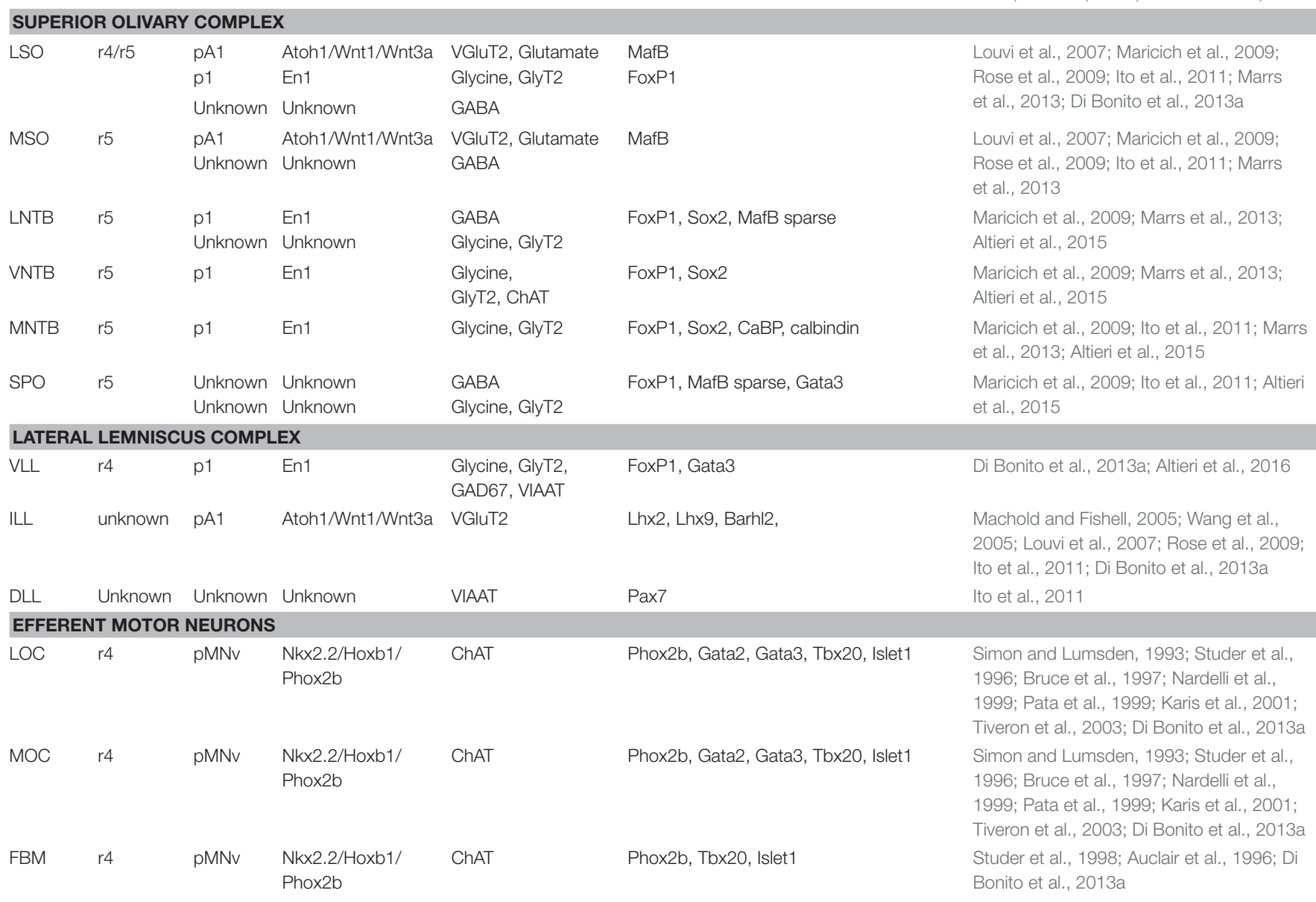

The table summarizes the AP and DV origin of auditory nuclei, their genetic lineage, expression of neurotransmitter and genetic markers, and corresponding references. The genetic markers separated by comma refer to their expression in the entire structure, whereas the ones separated by a slash refer to their expression in specific cell types, listed in parenthesis. 
Table 1). In particular, $\mathrm{r} 2$ gives rise to the AVCN and associated shell, whereas $\mathrm{r} 3 / \mathrm{r} 5$ contribute to the AVCN, DCN and shell and only poorly to the PVCN (Farago et al., 2006; Maricich et al., 2009). Differently, r4 largely contributes to the PVCN and the intermediate part crossing dorsoventrally the magnocellular core of DCN, but does not provide any granule cells, and only few r4-derived cells supply the AVCN (Di Bonito et al., 2013a).

\section{Molecular Determinants of the Lower Rhombic Lip Pattern Different Parts of the Cochlear Nuclear Complex}

Along the DV axis, the rhombic lip, the dorsal-most neuroepithelial cells of the developing hindbrain, and particularly the lower rhombic lip (LRL) caudal to $\mathrm{r} 1$, contributes to all divisions of the cochlear nuclear complex: the magnocellular core regions of the AVCN, PVCN and DCN, as well as granule cells of the microneuronal shell (Wang et al., 2005; Farago et al., 2006; Nichols and Bruce, 2006). The whole rhombic lip expresses Wnt1, a member of the Wnt gene family highly implicated in several developmental processes (Awatramani et al., 2003; Landsberg et al., 2005; Nichols and Bruce, 2006). In particular, $W n t 1^{+}$LRL cells from $\mathrm{r} 2$ will give rise to the AVCN and associated shell, while $\mathrm{r} 3 / \mathrm{r} 5$ Wnt1-derived cells contribute to the AVCN, PVCN (poorly), DCN and shell (Farago et al., 2006; Figures 5A,B, Table 1). By using the intersectional and subtractive genetic fate mapping via a sophisticated Flp-FRT and Cre-loxP-based dual lineage-tracing system, Farago and collaborators showed that the magnocellular core of the $\mathrm{CN}$ receives contributions from LRL and non-lip progenitors lying ventral to the auditory lip, whereas granule cells derive mainly from LRL (Farago et al., 2006). Interestingly, a graded expression pattern of Wnt1 along the LRL, high dorsal to low ventral, activates downstream targets in a dose- and spatiallydependent manner defining thus distinct DV progenitor domains (Figures 2B, 5B). In particular, the domain defined as A1, which lies within the Wnt ${ }^{\text {high }}$ territory, expresses the proneural transcription factor mouse atonal homolog 1 (Math1 or Atoh1) and contributes to distinct auditory nuclei. Atoh1 is expressed in cycling cells of the ventricular zone (VZ) and in presumed progeny neurons in the immediately lateral mantle zone (MZ) (Landsberg et al., 2005; Figure 5B). In the peripheral auditory system, Atoh 1 is both necessary and sufficient to direct the differentiation and maintenance of cochlear hair cells (Bermingham et al., 1999). Different Atoh $1^{\text {LacZ }}$ and Atoh $1^{\text {Cre }}$ knock-in or transgenic mice lines using the Atoh 1 enhancer have allowed to determine the different neuronal populations originating from the $A t o h 1^{+}$domain, whereas the availability of Atoh $1^{\text {null }}$ and conditional mice has unraveled distinct Atoh1 functions in the central auditory system (Wang et al., 2005; Fujiyama et al., 2009; Maricich et al., 2009; Rose et al., 2009). Fate map studies have shown that cells derived from the $\mathrm{r} 3 / \mathrm{r} 5 \mathrm{Atoh}^{+}$domain contribute to several glutamatergic neuronal populations of the VCN (mainly to the AVCN) and DCN, as well as to cochlear granule cells (Figures 5A-C). These nuclei are affected in the absence of Atoh1 demonstrating that Atoh1 is necessary for the fate determination of $\mathrm{CN}$ glutamatergic neurons (Fujiyama et al., 2009).

Granule cells migrate from the LRL into the developing CN via the cochlear extramural stream (CES). Both cochlear granule cells and their precursors express the homeobox gene Barhll, described to act downstream of Atoh1 (Farago et al., 2006; Rose et al., 2009). Other Atoh1-dependent factors, such as Lhx2 and $L h \times 9$, are instead expressed respectively in the DCN/VCN or only in the DCN (Table 1). As expected, expression of all these markers is lost in Atoh $1^{\text {null }}$ hindbrains (Rose et al., 2009), whereas selective deletion of Atoh 1 from $\mathrm{r} 3 / \mathrm{r} 5$ results in the loss of the entire AVCN with the exception of a small posterior portion, and in the reduction of both the PVCN and DCN (Maricich et al., 2009). As a consequence, mutant mice have an abnormal auditory brainstem response (ABR) with threshold elevations and absence of the late waveforms generated by the brainstem relay stations. Thus, the auditory nerve properly receives sound information from the inner ear hair cells, but the signal does not propagate beyond the auditory nerve with consequent deafness. The $\mathrm{CN}$ dysfunction also causes secondary loss of spiral ganglion (SG) and SOC neurons. The reduction of SG neurons probably accounts for the decreased compound action potentials amplitude found in the conditional mutant mice (Maricich et al., 2009). Thus, Atoh1 represents a true master gene in the development of $\mathrm{r} 3 / \mathrm{r} 5$ derived auditory structures.

The bHLH transcription factor Atoh7 (also known as Math5, mouse atonal homolog 5) is expressed in migrating cells of the LRL Atoh1-lineage and is also regulated by Atoh1 (Hufnagel et al., 2007). In the $\mathrm{CN}, A t o h 7^{+}$cells represent the glutamatergic globular and small spherical bushy neurons distributed with high density in the AVCN and rostral PVCN, and low density in the caudal PVCN (Saul et al., 2008; Table 1). In particular, the spherical bushy cells are predominantly located in the AVCN, while the globular bushy cells are found in the central AVCN and extend into the PVCN. Interestingly, Atoh $7^{\text {null }}$ mice have normal $\mathrm{CN}$ dimensions although $A t o h 7^{+}$cells are smaller. As a result, ABR tests of the mutant mice revealed decreased II-III and increased III-IV the interpeak latencies. Since the spherical and globular bushy cells and their targets generate peaks II-III and are involved in the integration of binaural auditory information, required for the sound spatial localization, the latency differences due to the dysfunction of Atoh $7^{+}$neurons are consistent with a disruption of binaural processing mechanisms (Saul et al., 2008).

\section{Other DV Domains and Their Molecular Determinants Contributing to the Auditory Cochlear Nuclear Complex}

The pancreatic transcription factor 1 a (Ptf1a) encodes for a basichelix-loop-helix $(b H L H)$ protein expressed in neural progenitors of the A4 and B1 dorsal domains in the mouse hindbrain (Figure 5B). Ptfla-derived neuronal progenies contribute predominantly to the DCN, whereas fewer cells populate the VCN (Yamada et al., 2007; Fujiyama et al., 2009; Figures 5A-C). 
Particularly, $\mathrm{CN}$ excitatory (glutamatergic) neurons arise from the Atoh1-expressing LRL, whereas inhibitory (GABAergic or glycinergic) neurons derive from the Ptfla-expressing neuroepithelial domain (Fujiyama et al., 2009; Figure 5B). Thus, the Ptfia ${ }^{+}$domain supplies GABAergic golgi, ML-stellate cells and glycinergic cartwheel and tuberculo-ventral neurons within the DCN, whereas the glutamatergic unipolar brush, giant and fusiform cells are derived from the Atoh $1^{+}$domain (Figure 5C). Similarly, the Atoh $1^{+}$domain contributes to glutamatergic octopus, globular bushy, spherical bushy and T-stellate cells in the VCN, whereas the Ptfla-lineage gives rise only to glycinergic D-stellate cells. The granule cells in the microneuronal shell are instead glutamatergic Atoh1-derivatives. Accordingly, production of inhibitory or excitatory cochlear neurons is severely depleted in Ptf1a ${ }^{\text {null }}$ or Atoh $1^{\text {null }}$ embryos respectively, supporting a specific role for Ptfla and Atoh1 transcription factors in the development of these populations. However, VCN and DCN neurons with similar electrophysiological profiles (inhibitory or excitatory) derive from the same DV neuroepithelial domains but differentiate into distinct subtypes of inhibitory (e.g., golgi, cartwheel, etc.) or excitatory (e.g., octopus, globular bushy, etc.) neurons. This depends most probably on the integration of the same DV molecular profile with different AP rhombomere-specific genetic pathways. To support this issue, the intersectional genetic fate mapping using subtype- and rhombomere-specific transgenic lines will represent the most appropriate tool to characterize molecular complex mechanisms that generate the vast diversity of $\mathrm{CN}$ neurons, and correlate their origin to their neuronal fate and function.

Finally, Bhlhb5 (also known as Bhlhe22) is a neuralspecific transcriptional repressor expressed in the DCN during embryonic and postnatal development by the unipolar brush (excitatory) and cartwheel (inhibitory) cells (Cai et al., 2016; Table 1). Bhlhb5 is required for proper development, ontogeny and survival of DCN neurons, since mice lacking Bhlhb5 show a dramatically reduced number of unipolar brush and cartwheel cells. The intersectional genetic strategy using a Bhlhb5Flpo (an optimized version of the Flp recombinase; Kranz et al., 2010), and a PtflaCre transgenic line was used to specifically label the inhibitory Bhlhb5-expressing cartwheel cells. However, the authors show differences in the subpopulations marked by the Bhlhb5Flpo and Bhlhb5Cre mouse lines. Indeed, while the Flpo line identifies cells with high Bhlhb5 expression levels over an extended period, the Cre mouse labels all cells, even if Bhlhb5 expression is low and/or transient (Cai et al., 2016). Thus, the two lines have distinct patterns of recombination, likely due to the fact that the Cre-recombinase is a more active enzyme than the Flpo-one in mammalian cells. Finally, a systematic analysis of the transcriptome of individual rhombomeres (r2-r5) has revealed that Bhlhb5 expression is upregulated in $\mathrm{r} 4$ and restricted to the $\mathrm{r} 4$ ventral motor neuron domain and to longitudinal stripes in alar r4 (Chambers et al., 2009). Future studies are necessary to determine whether these dorsal domains contribute to Bhlhb5expressing neurons in the DCN in a rhombomere-specific manner.

\section{The Lateral Lemniscus Complex Plays Different Roles in Sound Processing}

The lateral lemniscus (LL) complex, one of the major stations along the hearing path, is subdivided into ventral (VLL), intermediate (ILL), and dorsal (DLL) nuclei. The VLL receives inputs mainly from the contralateral ear and project to the ipsilateral inferior colliculus (IC) (monaural system), whereas the DLL receives inputs from both ears mainly through connections with the superior olive and projects to both IC (binaural system) (Malmierca and Merchán, 2004; Figures 3A, 6B, 7A,B). The VLL is considered a nucleus primarily involved in processing information concerning the temporal or spectral quality of auditory stimuli (Zhang and Kelly, 2006). The DLL instead is mainly required in the mechanisms of sound localization (Grothe et al., 2010).

Regarding their origins, the VLL derives from basal $\mathrm{r} 4$ (Di Bonito et al., 2013a), whereas the rhombomeres that contribute to the ILL and DLL have still to be identified (Figures 4A, 5A,B). The VLL r4-derived neurons migrate rostrally from the basal longitudinal zone along the growing lateral lemniscus tract that ascends through the rostral hindbrain into the inferior colliculus (IC) located in the midbrain (Di Bonito et al., 2013a). The ipsilateral r4-derived VLL neurons and presumably the r4derived projection neurons of the contralateral $\mathrm{CN}$ contribute to form the lateral lemniscus tract that projects to the IC, sends collaterals to the superior colliculus and extends into the medial geniculate nucleus of the thalamus (Di Bonito et al., 2013a; Figure 6B). The r4-derived VLL neurons project to the central nucleus of the IC, whereas $\mathrm{r} 4$-derived projection neurons of the $\mathrm{CN}$ that contribute to the lateral lemniscus tract, are most likely fusiform cells in the DCN that project to the contralateral IC and medial geniculate nucleus. A recent report has shown that glycinergic and double glycinergic/GABAergic VLL neurons derive from a lineage positive for the homeodomain transcription factor Engrailed (En1) (Altieri et al., 2016), which is expressed within the V1 postmitotic domain in the spinal cord and hindbrain (Gray, 2008; Alaynick et al., 2011) (Figures 2B, 5A,B). En1 is necessary for their survival, but not for their generation or positioning, and indeed $E n 1$ deletion causes glycinergic/GABAergic VLL neuronal death during late embryonic and early postnatal development (Altieri et al., 2016). Expression of the Vesicular Glutamate Transporters VGluT (VGluT1, VGluT2) for glutamatergic neurons, and of the Vesicular Inhibitory Amino Acid Transporter VIAAT (also called $V G A T$ ) for both GABAergic and glycinergic neurons (Ito et al., 2011) confirmed the inhibitory nature of VLL neurons (Di Bonito et al., 2013a; Altieri et al., 2016). Ito et al. (2011) also showed that while DLL neurons are mainly inhibitory with dense clusters of VIAAT ${ }^{+}$neurons and few VGluT ${ }^{+}$neurons, ILL neurons are mainly excitatory with a majority of neurons expressing VGluT1 and/or VGluT2, and a minority expressing VIAAT. These new data indicate that the Atoh1-derived VGluT2 glutamatergic component of the LL was inappropriately considered as DLL in previous works (Machold and Fishell, 2005; Louvi et al., 2007; Rose et al., 2009; Di Bonito et al., 2013a), since it most likely represents the ILL. The authors also showed that few VGluT ${ }^{+}$ 


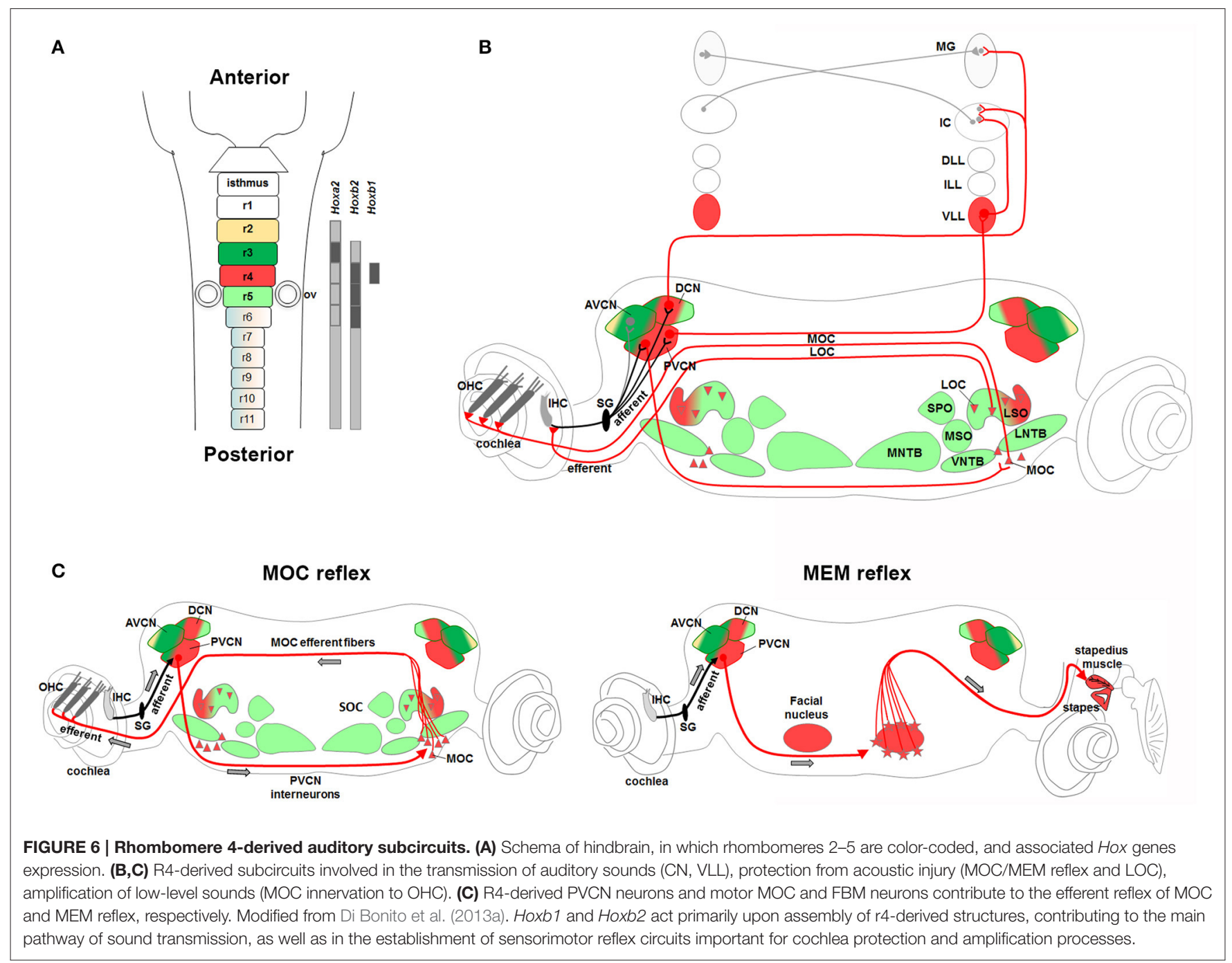

neurons are found in the VLL, and that cells expressing only VGluT1 form a separate population of small neurons, most likely granule cells, along the surface of the lateral lemniscus. These neurons form a continuous band together with the granule cells of the cochlear nucleus, medial cerebellar peduncle and cerebellum. Finally, cells derived from the Wnt3a-lineage also show a similar type of distribution around the VLL, besides contributing to the ILL nucleus (Louvi et al., 2007). More experiments are therefore necessary before understanding the precise origin of ILL and DLL neurons.

\section{The Superior Olivary Complex as the Major Component of Sound Localization}

The superior olivary complex (SOC) is a group of brainstem nuclei that act in multiple aspects of hearing and is an important component of the ascending and descending pathways of the auditory system. The nuclei that form the SOC are: the lateral (LSO) and medial (MSO) superior olive, the medial (MNTB), ventral (VNTB), and lateral (LNTB) nuclei of the trapezoid body, the superior paraolivary (SPO) nucleus and the periolivary nuclei
(Figure 4C). While $\mathrm{r} 5$ gives rise to the majority of SOC nuclei (LSO, MSO, MNTB, VNTB, and LNTB) (Maricich et al., 2009; Marrs et al., 2013), r4 contributes to the VGluT2 ${ }^{+}$subpopulation of the LSO and to some periolivary nuclei within the SOC (Di Bonito et al., 2013a and unpublished data; Figure 4C). An r3 additional contribution to the MNTB nucleus has also been suggested (Maricich et al., 2009), whereas nothing is known about the AP origin of the SPO. SOC nuclei have also distinct DV origins: LSO and MSO derive predominantly from the rhombic lip, whereas the MNTB, VNTB, and LNTB nuclei are likely basal plate-derivatives (Maricich et al., 2009; Rose et al., 2009; Marrs et al., 2013; Figures 5B,D, Table 1). In particular, LSO and MSO originate from the Atoh1- (Maricich et al., 2009), Wnt1- and Wnt3a-lineages (Louvi et al., 2007; Marrs et al., 2013), whereas MNTB, VNTB, LNTB mainly derive from the En1lineage (Marrs et al., 2013) that also contributes partially to the LSO. As described above, Atoh $1^{+}$derivatives are glutamatergic (Maricich et al., 2009; Rose et al., 2009), whereas En1-derived neurons have multiple neurotransmitter phenotypes: glycinergic, cholinergic and GABAergic (Altieri et al., 2015). Indeed, deletion 
of Atoh 1 in $\mathrm{r} 3 / \mathrm{r} 5$ causes glutamatergic neuronal loss in LSO and MSO and secondary reduction of neurons in the MNTB, VNTB, and LNTB (Maricich et al., 2009). Conditional deletion of En1 in $\mathrm{r} 3 / \mathrm{r} 5$ instead leads to the absence of MNTB and VNTB nuclei, which are the two nuclei entirely derived from the En1-lineage (Jalabi et al., 2013). A further report has also shown that LSO and MNTB glycinergic neurons, VNTB glicinergic/cholinergic neurons and the GABAergic component of the LNTB derive from $E n 1$ and are lost in $\mathrm{r} 3 / \mathrm{r} 5$ En 1 conditional mutant mice, as a consequence of neuronal death (Altieri et al., 2015).

\section{Brainstem Subcircuits Involved in Sound Localization}

Proper spatial information on the horizontal (azimuth) and vertical (elevation) directions and distance of the sound source from the listener is required for sound localization. Sound localization in vertical plane and in horizontal front/back position is a monaural pathway, which uses modifications in the sound spectra produced by the interactions of sound with the asymmetric external ear (Grothe et al., 2010). The DCN is particularly specialized in the first processing of spectral localization cues and in conveying these signals to the IC (Cant and Benson, 2003; Oertel and Young, 2004; Grothe et al., 2010). Mechanisms of localization for incoming sound source in the horizontal plane (excluding front/back localization) are instead based on two different binaural pathways processing differences in the interaural time (ITDs) and interaural level or intensity (ILDs or IIDs) between sounds reaching the two ears (Kandler and Gillespie, 2005; Grothe et al., 2010; Figures 7A,B). The ITDs depend on the different distance that a sound wave must travel to reach the near and far ears, which will determine the difference in the arrival time. ILDs depend on the shadowing effect of the head on sound that reaches the ear further from the source, which creates differences in the sound level at the two ears. The binaural ILDs and ITDs for the azimuthal sound localization are first processed by the LSO and MSO, respectively (Kandler and Gillespie, 2005; Grothe et al., 2010).

LSO neurons encode ILDs by integrating excitatory inputs from the ipsilateral ear with inhibitory inputs from the contralateral ear so that neurons are completely inhibited when sound at the contralateral ear is more intense, and highly responsive when sound at the ipsilateral ear is more intense (Figure 7A). In particular, LSO principal neurons receive excitatory glutamatergic inputs from the small spherical bushy cells of the ipsilateral AVCN and inhibitory glycinergic inputs from the MNTB, which in turn is activated by excitatory glutamatergic inputs from the globular bushy cells of the contralateral AVCN. LSO neurons send excitatory projections to the contralateral DLL and IC and inhibitory ones to the ipsilateral DLL. In the IC, ILDs are created by the convergence of monaural contralateral excitatory inputs from the AVCN and binaural inhibitory inputs from the DLL. MSO principal cells with bipolar morphology encode ITDs by integrating bilateral excitatory inputs from both cochlear nuclei and bilateral inhibitory inputs through the LNTB and the MNTB (Figure 7B). MSO neurons receive tonotopic binaural excitatory glutamatergic inputs from large spherical bushy cells in both AVCNs with ipsilateral axons synapsing on the lateral dendrites and contralateral axons on the medial ones. In addition, MSO neurons also receive binaural inhibitory glycinergic inputs to their soma from the ipsilateral LNTB and MNTB, which in turn are stimulated by excitatory glutamatergic inputs of ipsilateral and contralateral AVCN globular bushy cells, respectively. Finally, MSO neurons send excitatory projections to the DLL and IC.

Components of the spatial sound localization pathways have different rhombomeric origins and derive from specific lineages. Atoh1-derived $A t o h 7^{+}$spherical and globular bushy cells in the AVCN originate from $\mathrm{r} 2 / \mathrm{r} 3$, while En1-lineage glycinergic neurons of the MNTB derive from $r 5$, supporting the main contribution of these rhombomeres to the sound localization process. However, the ability to localize sounds and glycinergic innervation of the SOC persist after genetic deletion of the MNTB, observed upon loss of En1 function in $\mathrm{r} 3 / 5$ (Jalabi et al., 2013). In these mice, there is a complete lack of MNTB and VNTB neurons, whereas LNTB neurons and the functional glycinergic innervation of the LSO and SPO are relatively preserved. This could be due either to the developmental compensation by other regions of the central auditory system, or to parallel inhibitory innervation, normally existent but obscured in wild type animals in which glycinergic MNTB innervation dominates. Finally, it suggests that there are other sources of glycinergic innervation and other auditory structures that might contribute to the sound localization process (Jalabi et al., 2013; Altieri et al., 2014).

\section{Efferent Motor Neurons Contribute to the MOC and MEM Reflexes}

Hair cells in the inner ear receive efferent innervation through the VIIIth cranial nerve from motor neurons located in the hindbrain (Figure 3B). The inner ear efferent (IEE, also known as contralateral vestibuloacoustic or CVA) neurons originate from the progenitor domain of visceral motor neurons ( $\mathrm{pMNv}$ ) in ventral (basal) r4 (Simon and Lumsden, 1993; Bruce et al., 1997), which also gives rise to another efferent neuronal populations, the facial branchiomotor (FBM) neurons of the VIIth cranial nerve (Auclair et al., 1996) (Figures 5A,B). R4-derived IEE neurons can be subdivided into vestibular (VEN) and cochlear (CEN) efferent nuclei, according to their targets. CEN form two groups of olivocochlear neurons (OC): the lateral (LOC) and medial (MOC) olivocochlear efferent neurons, located within the LSO and in the medioventral portion of the SOC as spread cells, respectively (Brown and Levine, 2008; Figures 4C, 5D). LOC neurons project mainly to the ipsilateral cochlea and terminate on afferent sensory dendrites contacting IHCs, modulate cochlear nerve excitability and protect the cochlea from acoustic injury (Kujawa and Liberman, 1997; Darrow et al., 2007; Figure 3B). MOC neurons instead project mainly to the contralateral cochlea innervating directly OHCs and modulate the cochlear amplification process by inhibiting OHCs motility through the MOC reflex (Ashmore et al., 2010; Figure 3B). The MOC reflex is a three-neuron pathway (Guinan, 2006): (i) sound excites auditory afferent neurons of the auditory nerve (SG neurons) that synapse on cochlear hair cells in the periphery 


\section{A Interaural level difference (ILD)}

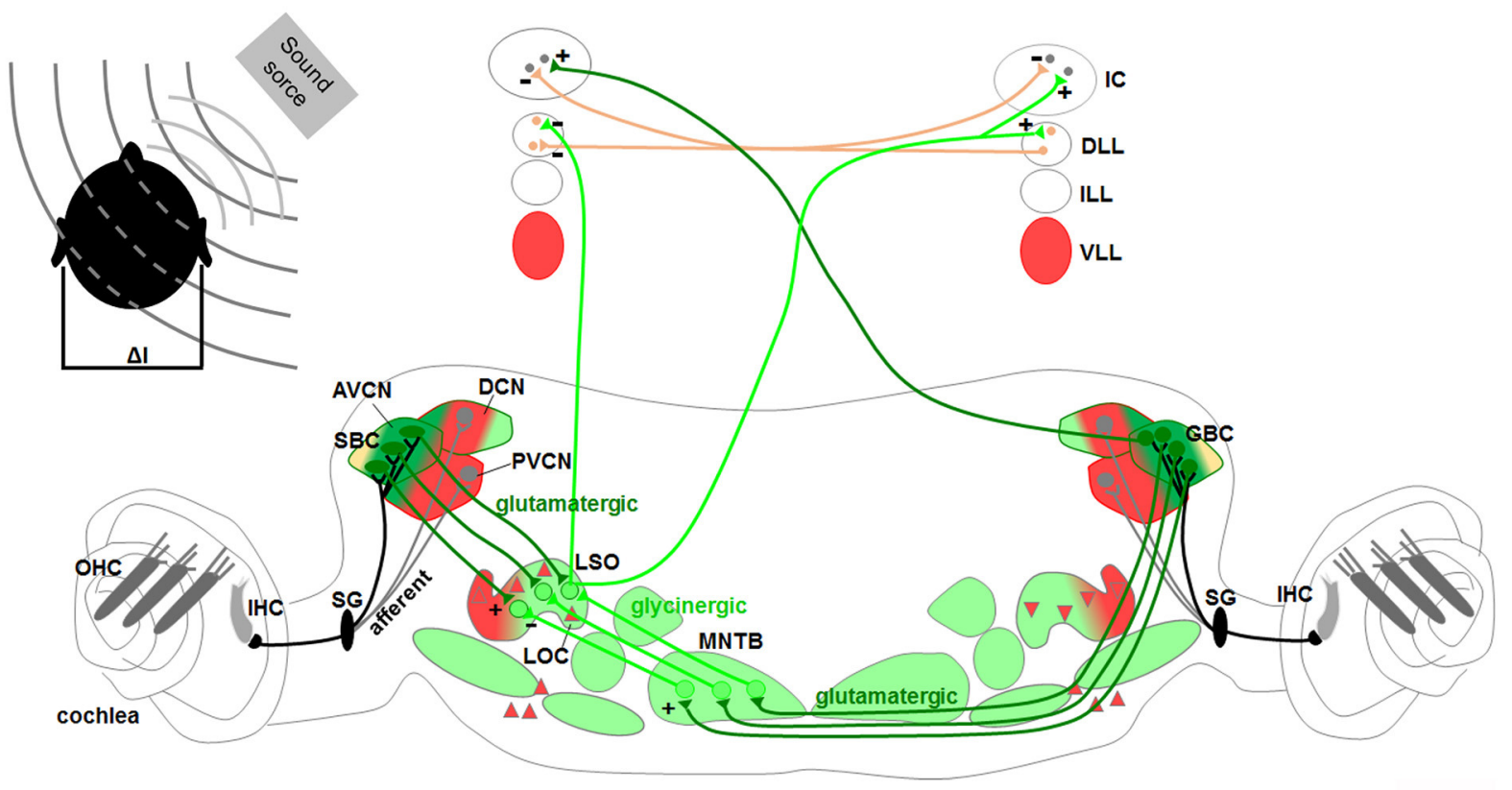

\section{B Interaural time difference (ITD)}

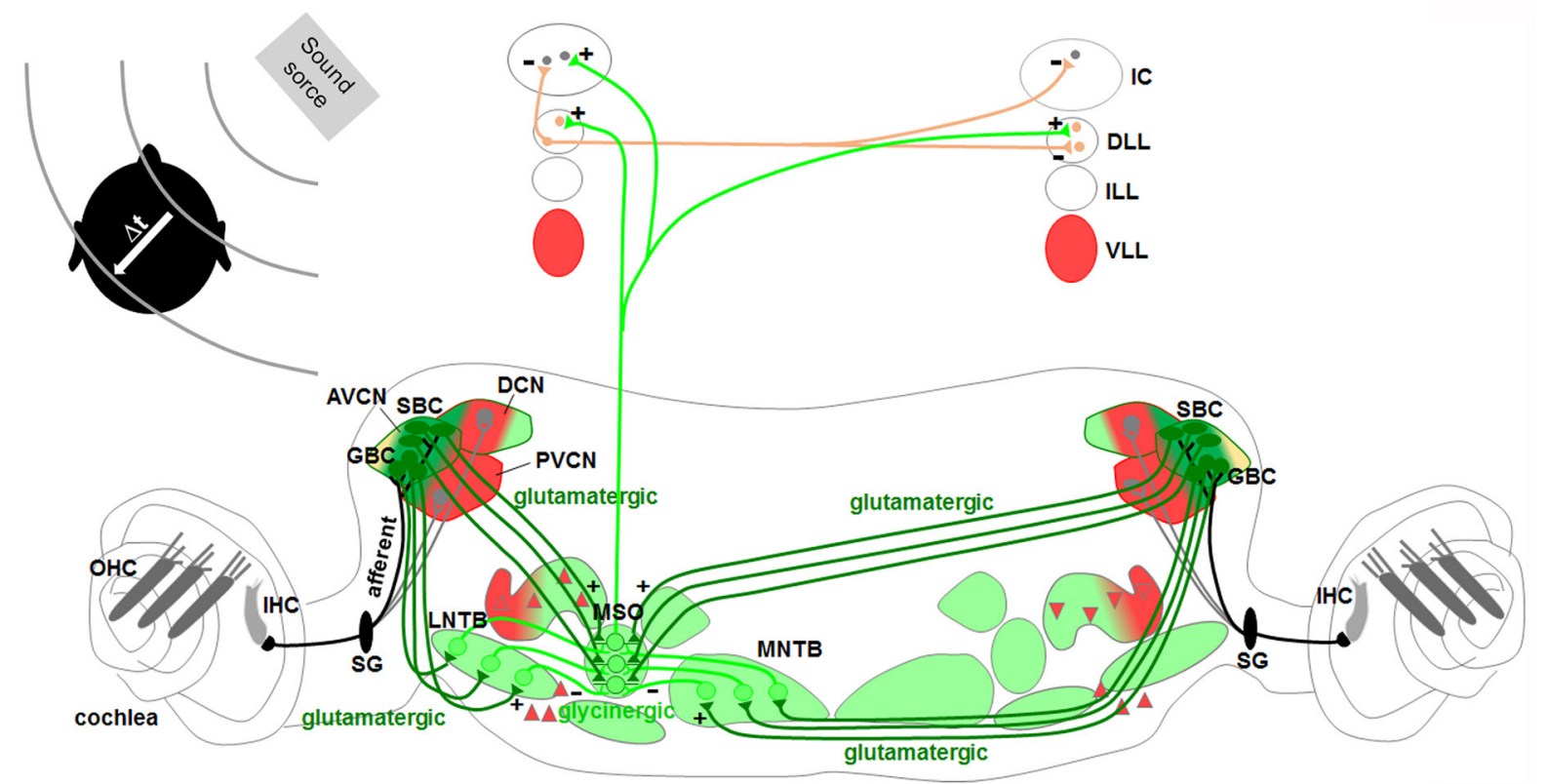

FIGURE 7 | Rhombomeres 2, 3, and 5-derived auditory subcircuits. The color code of the auditory nuclei is referred to the schema in Figure 6A. (A,B) r2/r3/r5-derived subcircuits involved in the sound localization by (A) interaural level difference (ILD) and (B) interaural time difference (ITD), modified from Grothe et al. (2010). ILD (A) and ITD (B) are processed by neurons of r2/r3-derived AVCN, and r5-derived MNTB and LSO or MSO, respectively. Hoxa2 contributes to AVCN development and connectivity in the sound localization circuit, mainly formed by r2, r3, and r5.

and innervate reflex interneurons in the PVCN; (ii) these PVCN interneurons are planar multipolar cells (corresponding to the Tstellate or type I multipolar cells) (de Venecia et al., 2005; Darrow et al., 2012) and send axons across the midline to innervate MOC neurons; (iii) MOC neurons project to cochlear OHCs and inhibit cochlear amplification reducing basilar membrane 
responses to low-level sounds (Figures 3B, 6C). Another reflex which protects the ear from overstimulation is the middle ear muscle (MEM) reflex, formed by facial (FBM) and trigeminal (TBM) branchiomotor neurons that innervate muscles of the stapedius attached to the head of the stapes and tensor tympani inserted onto the malleus, respectively (Liberman and Guinan, 1998; Lee et al., 2006). Thus, by stiffening the ossicular chain and reducing the amplitude of sound transmission through the middle ear, the MEM reflex offers protection from acoustic overstimulation. In particular, the stapedial reflex pathway begins with the excitation of the auditory nerve that in turn acts on MEM reflex interneurons in the VCN (Figure 3B, 6C). Output from the VCN leads to the excitation of r4-derived FBM motor neurons and consequent contraction of the stapedius muscles attached to the stapes. The stapedius muscles and stapes are both derivatives of the 2nd pharyngeal arch neural crest cells originating from $\mathrm{r} 4$ (Anthwal and Thompson, 2016).

Hence, r4 represents a crucial rhombomere in the development of the central auditory system (Figure 6). While r4-derived CN and VLL contribute to the ascending sound transmission pathway, ventral r4-derived efferent neurons (MOC, LOC, and FBM) are involved in the processes of sound amplification and protection from acoustic injury. R4-derived cochlear sensory neurons (PVCN interneurons) form jointly with $\mathrm{r} 4$ basal plate-derived motor neurons (FBM and MOC) two distinct auditory sensorimotor feedback subcircuits required in modulating incoming acoustic stimuli at the level of the middle and inner ear (Di Bonito et al., 2013a). On the contrary, sound localization pathways are mainly derived from r2, r3, and r5 (Figure 7). Therefore, structurally and functionally interconnected components of the auditory system are specified in a rhombomere-specific manner and different rhombomeres give rise to distinct subcircuits with diverse functions.

\section{Considerations in the Use and Interpretation of Rhombomeric-Specific Transgenic Lines}

The rhombomere-specific Cre transgenic mice have represented a powerful tool for identifying and characterizing the origin of the different components of the central auditory system. However, some aspects need to be taken into account for a correct interpretation of published data. The Egr2Cre ( $33 /$ r5Cre) (Voiculescu et al., 2000) has been regularly used to fate map or alter r3- and r5-derived neuronal populations (Wang et al., 2005; Maricich et al., 2009; Rose et al., 2009), because neither r3- or r5-specific Cre lines were available, or anyway used in these studies. However, it is important to consider that there is no way to distinguish $\mathrm{r} 3$ - from $\mathrm{r} 5$-specific derivatives using this transgenic line. Thus, to avoid misleading interpretations, it is important to take into account that the mapped populations not necessarily derive from both rhombomeres but could arise only from $\mathrm{r} 3$ or $\mathrm{r} 5$. In addition, it can be risky to presume the rhombomeric origin of a specific cell population just by subtracting it from the previously mapped one. For example, differently from what was initially hypothesized (Farago et al., 2006), r4 does not contribute to the cochlear granule cells of the microneuronal shell (Di Bonito et al., 2013a), which instead origin from $\mathrm{r} 2$ and $\mathrm{r} 3$, as confirmed by ectopic production of granule cells in Hoxb1 mutant mice in which $\mathrm{r} 4$ acquires an r3 identity (Farago et al., 2006; Di Bonito et al., 2013a). Thus, it seems unlikely that they also originate from $\mathrm{r} 5$, as indirectly hypothesized using the Egr2Cre line. Moreover, the MNTB might only derive from $\mathrm{r} 5$ since it is located in $\mathrm{r} 5$ (Marrs et al., 2013), and no migration from $\mathrm{r} 3$ has ever been described. On the other hand, the r4-derived DCN region occupies only an intermediate sector within the magnocellular core of the DCN (Di Bonito et al., 2013a) between two small portions; thus, while the posterior DCN derives from r5, as already reported (Farago et al., 2006; Maricich et al., 2009), the anterior part most likely originates from $\mathrm{r} 3$, not previously taken into account in the fate map analysis of the Egr2Cre line (Figure 4B). In this scenario, the AVCN and granule cells derive from $\mathrm{r} 2$ and $\mathrm{r} 3$ with only few cells of $\mathrm{r} 4$ origin in the AVCN, whereas the PVCN is mainly an r4-derived structure with a modest contribution of $r 3$, and the DCN receives a multi-rhombomeric contribution from $r 3, r 4$ and r5 (Figures 4A-C, Table 1). Finally, before the publication of a very specific $r 4$-Cre transgenic line (called b1-r4Cre) (Di Bonito et al., 2013a), a Hoxb1Cre knock-in line was used to fate map r4derivatives, but since Hoxb1 is also expressed caudal to 4 at early stages (Murphy et al., 1989; Arenkiel et al., 2003), studies using this line cannot exclude a contribution of posterior rhombomeres (Maricich et al., 2009; Marrs et al., 2013).

\section{ROLE OF HOX GENES IN THE ASSEMBLY OF CENTRAL AUDITORY SUBCIRCUITS}

As previously mentioned, Hox genes are homeotic genes required in conferring rostrocaudal identity of rhombomeres along the AP axis during hindbrain segmentation, and in specifying distinct neuronal populations along the DV axis during neurogenesis (Tumpel et al., 2009; Philippidou and Dasen, 2013; Di Bonito et al., 2013b). In the hindbrain, PG 1-7 Hox genes display expression patterns with defined rostral boundaries according to the $3^{\prime}$ to $5^{\prime}$ collinearity rule, whereby $3^{\prime}$-located genes will have a more rostral expression boundary than genes located more $5^{\prime}$ in the same cluster (Duboule and Dolle, 1989; Graham et al., 1989; Wilkinson et al., 1989; Lumsden and Krumlauf, 1996; Marin et al., 2008; Tomas-Roca et al., 2016). Except r1, which is devoid of Hox expression, each rhombomere expresses a distinct Hox combinatorial code that specifies the identity and patterning program of each hindbrain segment (Krumlauf, 1993b; Maconochie et al., 1996; Tumpel et al., 2009).

Hox genes become progressively restricted along the DV axis into specific progenitor domains during neurogenesis contributing hence to proper specification of distinct neuronal subpopulations (Davenne et al., 1999; Gaufo et al., 2000, 2003, 2004; Pattyn et al., 2003a; Samad et al., 2004; Jacob et al., 2007). The early segmental Hox expression patterns are often maintained through later stages in subsets of rhombomerederived progenitors, postmitotic and projection neurons, which will contribute to specific developing brainstem nuclei. Several studies have demonstrated that Hox genes play important 
roles in several aspects of sensorimotor circuit development and assembly regulating neuronal fate, stereotypic neuronal migration and axon pathfinding patterns in a rhombomerespecific manner (Oury et al., 2006; Geisen et al., 2008; Chen et al., 2012; Di Bonito et al., 2013a, 2015; Di Meglio et al., 2013). Thus, rhombomere-specific (AP) and alar- to basal-restricted (DV) pools of neurons contribute to distinct functional pathways and circuits through the maintenance of differential combinations of Hox genes that, in turn, will continuously refine regional identity within the multi-segmental neuronal columns. This implies that single rhombomeres and their specific Hox gene combinations are involved in generating different components within distinct sensorimotor systems, contributing in this way to build the complex network of circuits and functional topographic connectivity in the mature hindbrain (Narita and Rijli, 2009; Di Bonito et al., 2013b; Philippidou and Dasen, 2013).

To this regard, mutations in human HOX genes have been correlated with hearing impairments (Quinonez and Innis, 2014; Willaredt et al., 2014). Homozygous mutations of HOXA1 are associated with the autosomal recessive Athabascan Brainstem Dysgenesis Syndrome (ABDS) and the Bosley-Salih-Alorainy Syndrome (BSAS) characterized by sensorineural deafness due to the absence or aplasia of the cochlea (Tischfield et al., 2005; Bosley et al., 2008). Furthermore, homozygous missense mutation in HOXB1 has been linked to sensorineural hearing loss in patients with Moebius syndrome (Webb et al., 2012). ABR tests have revealed bilateral mild to moderate high-frequency hearing loss with normal waveform latencies, whereas no distortion product otoacustic emission (DPOAE) was recorded in the cochlea, indicating abnormal cochlear $\mathrm{OHC}$ function. Finally, heterozygous nonsense (haploinsufficiency) or homozygous missense (reduced DNA binding affinity) mutations in HOXA2 causes a dominant or recessive bilateral microtia respectively, a rare congenital malformation of the external ear, as well as hearing loss (Alasti et al., 2008; Brown et al., 2013).

Can mouse genetics help us in better dissecting patients' hearing abnormalities? The PG1 Hoxal and Hoxb1 genes are activated in the mouse hindbrain by retinoic acid and expressed with an anterior border at the presumptive $\mathrm{r} 3 / \mathrm{r} 4$ boundary at early embryological stage before the formation of definitive rhombomeres (Marshall et al., 1994; Dupe et al., 1997; Studer et al., 1998; Figure 1). Hoxa1 transactivates Hoxb1 expression and both synergize in establishing Hoxb1 expression in $\mathrm{r} 4$ by binding to an $\mathrm{r} 4$ enhancer located in the $5^{\prime}$ promotor region (Studer et al., 1998). Then, Hoxb1 is selectively maintained in r4 by an autoregulatory loop which is repressed in adjacent rhombomeres (Studer et al., 1994; Popperl et al., 1995), and by persistent expression of Hoxb2 (Barrow and Capecchi, 1996; Gavalas et al., 2003; Pattyn et al., 2003a; Di Bonito et al., 2013a), whereas Hoxal is downregulated (Murphy and Hill, 1991). Hoxa2 and Hoxb2 are members of the PG2 Hox genes expressed with an anterior border at the $\mathrm{r} 1 / \mathrm{r} 2$ and $\mathrm{r} 2 / \mathrm{r} 3$ boundaries, respectively (Wilkinson et al., 1989; Hunt et al., 1991; Krumlauf, 1993a; Prince and Lumsden, 1994). Hoxa2 is expressed at low levels in $\mathrm{r} 2$ and $\mathrm{r} 4$ and at high levels in $\mathrm{r} 3$, particularly in a wide intermediate dorsal column and in a thinner more lateral one, the presumptive auditory column (Di Bonito et al., 2013a). Hoxb2 is co-expressed with Hoxa2 in $\mathrm{r} 3$ at low levels and with Hoxb1 in $\mathrm{r} 4$ at high levels (Di Bonito et al., 2013a). Hoxb1 upregulates Hoxb2 in $\mathrm{r} 4$ by binding to an $\mathrm{r} 4$-specific enhancer at the $5^{\prime}$ region of the Hoxb2 locus (Maconochie et al., 1997; Ferretti et al., 2000) and downregulates Hoxa2 (Di Bonito et al., 2013a), whereas Krox20 is an upstream regulator of Hoxa2 (Nonchev et al., 1996) and Hoxb2 (Sham et al., 1993) in r3 and r5. In the auditory system, Hoxb2 and Hoxa2 are still maintained in the CN, VLL, and SOC nuclei during prenatal and postnatal developmental stages (Narita and Rijli, 2009; Di Bonito et al., 2013a). Within the CN, Hoxa2 is mainly expressed in the AVCN, which originates from $\mathrm{r} 2$ and $\mathrm{r} 3$, whereas Hoxb2 is expressed in r4-derived structures, such as the PVCN, and in $\mathrm{r} 3$-derived AVCN and cochlear granule cells. Moreover, both genes are maintained in the $\mathrm{r} 3 / \mathrm{r} 4 / \mathrm{r} 5$ derived DCN (Farago et al., 2006; Di Bonito et al., 2013a).

Below, we will go into more details in the function of those Hox genes directly involved in the formation of the auditory system.

\section{Hoxa1 Acts as a Strong Selector Gene of r4 and $\mathrm{r} 5$ during Hindbrain Patterning}

Deletion of Hoxal leads to severe early defects in the hindbrain, since Hoxa $1^{\text {null }}$ embryos have a reduced $\mathrm{r} 4$ and almost a complete loss of r5 structures (Carpenter et al., 1993; Dolle et al., 1993; Mark et al., 1993). In the absence of these structures and their neural crest derivatives, null mice completely lack or have severe defects in the formation of middle ear ossicles (Lufkin et al., 1991; Chisaka et al., 1992; Mark et al., 1993), of the auricle and of the external acoustic meatus (Chisaka et al., 1992). The SG, the cochlear component of the VIIIth vestibulocochlear ganglion, is also lost. In the hindbrain, FBM and SOC nuclei are absent or strongly reduced, in agreement with reduction of $\mathrm{r} 4$ and almost complete loss of r5, whereas the VCN and DCN appear quite normal (Lufkin et al., 1991; Chisaka et al., 1992; Mark et al., 1993).

\section{Hoxb1 Acts as a Determinant Gene of r4 Sensory Identity and r4-Derived Auditory Neurons}

Differently from Hoxa1, Hoxb1 acts as a true homeotic gene by imprinting a $r 4$ identity in the developing hindbrain. Since $\mathrm{r} 4$ contributes to several auditory structures, as described above, Hoxb1 represents a key developmental gene playing a crucial role in the establishment of regional identity of motor (Studer et al., 1996; Gaufo et al., 2000; Gavalas et al., 2003; Pattyn et al., 2003a; Di Bonito et al., 2013a) and sensory r4-derived structures (Gaufo et al., 2004; Chen et al., 2012; Di Bonito et al., 2013a, 2015), partly by promoting Hoxb2 and repressing Hoxa2 expression in r4 (Maconochie et al., 1997; Ferretti et al., 2000; Tumpel et al., 2007; Di Bonito et al., 2013a). In Hoxb1 mutants, in which Hoxb1 is either constitutive $\left(H o x b 1^{\text {null }}\right)$ or conditionally (Hoxb $1^{\text {lateCKO})}$ inactivated in $\mathrm{r} 4, \mathrm{Hoxb} 2$ is reduced and Hoxa2 is increased at expression levels similar to those in $\mathrm{r} 3$ (Di Bonito et al., 2013a). This is also observed in Hoxb2 $2^{\triangle K O}$ embryos, in which Hoxb1 fails to be maintained in $\mathrm{r} 4$. The re-patterning of $\mathrm{r} 4$ into an $\mathrm{r} 3$ like identity, as a result of Hoxb1 inactivation, ultimately leads to the loss of specific r4-derived auditory nuclei (FBM, MOC, LOC, 
VLL, and PVCN) and to the ectopic formation and functional acquisition of neuronal populations that normally derive from r3 (TBM, AVCN and cochlear granule cells) (Studer et al., 1996; Di Bonito et al., 2013a). Hoxb1 lateCKO and Hoxb2 $2^{\Delta K O}$ mutants exhibit a similar though milder phenotype than Hoxb1 $1^{\text {null }}$ mice, since early Hoxb1 expression is able to partially specify $\mathrm{r} 4$ identity in these mutants, but failure to maintain Hoxb1 at later stages inhibits further development of r4-derived auditory nuclei (Di Bonito et al., 2013a). This concerns mainly the r4-derived nuclei that are developing while Hoxb1 is inactivated (FBM, OC, and VLL), whereas nuclei generated after Hoxb1 inactivation, such as the $\mathrm{CN}$, have similar defects in all mutants.

Hoxb1 is an important determinant gene in the r4-derived $\mathrm{CN}$ development in part by inhibiting a r3-like genetic pathway. One of the key Hox genes involved in patterning the AVCN in $r 3$ is Hoxa2, which is instead expressed at low levels in r4 differentiating cells, playing thus only a minor role in patterning r4-derived CN (Di Bonito et al., 2013a). In the absence of Hoxb1, Hoxa2 expression in $\mathrm{r} 4$ is increased at similar levels to r3, whereas Hoxb2 is downregulated (Di Bonito et al., 2013a; Figure 8). Hoxa2 and Atoh7, normally highly expressed in r3-derived AVCN neurons, are now ectopically upregulated in the r4-derived PVCN of Hoxb $1^{\text {null }}$ mutants leading ultimately to a change of PVCN to AVCN identity and abnormal connectivity pattern. Ectopic Atoh $7^{+}$glutamatergic neurons abnormally differentiate in the mutant PVCN acquiring the fate of spherical bushy cells (Di Bonito et al., 2013a), which are normally r3derived AVCN neurons produced by the Atoh1 domain (Farago et al., 2006; Saul et al., 2008; Fujiyama et al., 2009; Maricich et al., 2009). As a consequence, the AVCN-like mutant neurons of PVCN abnormally project to the MNTB, the physiological target of spherical bushy cells (Saul et al., 2008; Di Bonito et al., 2013a). Moreover, r4-derived mutant cells acquire the identity of granule cells, which normally do not originate from $\mathrm{r} 4$ but from the Atoh $1^{+}$domain in $\mathrm{r} 2 / \mathrm{r} 3$, and massively invade the glutamatergic microneuronal shell, which maintains Hoxb2 expression. The ectopic production of glutamatergic granule cells and of $A t o h 7^{+}$ neurons in the mutant $\mathrm{r} 4$-derived $\mathrm{CN}$ seems to be correlated with increased Atoh1 expression observed at early stages. This is in accordance with the fact that Atoh1 regulates Atoh7 expression levels, and that granule cells and $A t o h 7^{+}$neurons are both glutamatergic Atoh1-derivatives (Hufnagel et al., 2007). It is thus
A
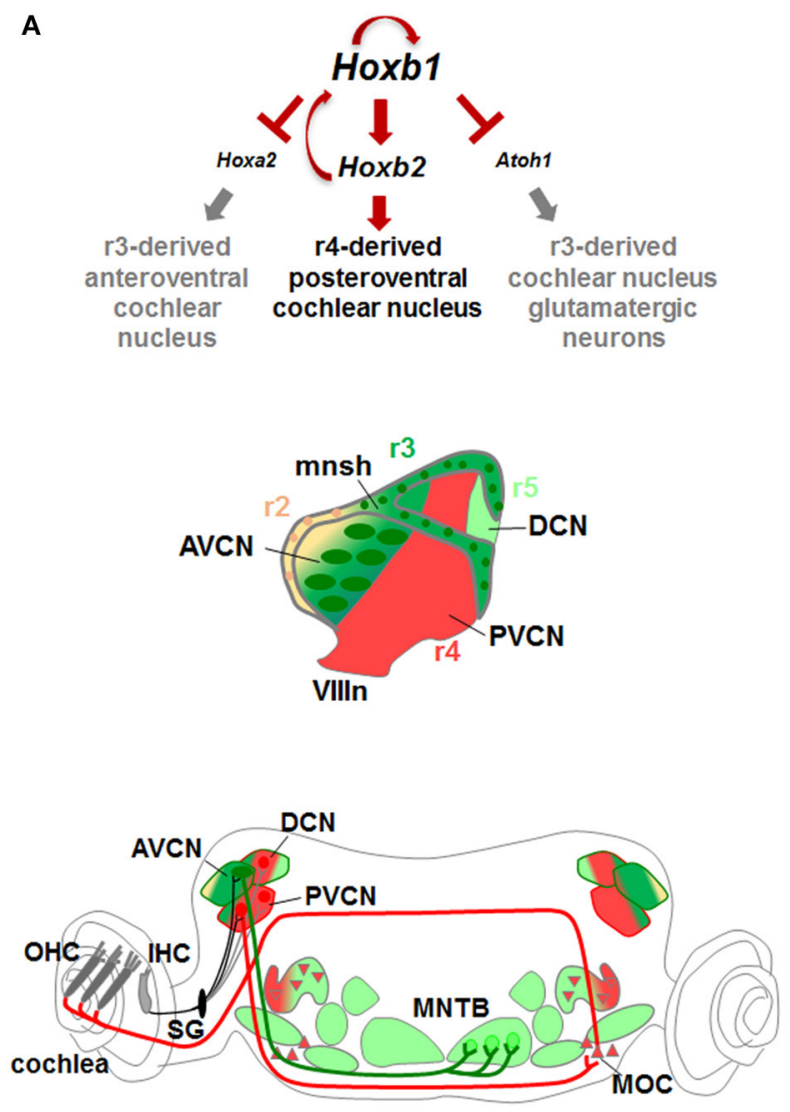

B
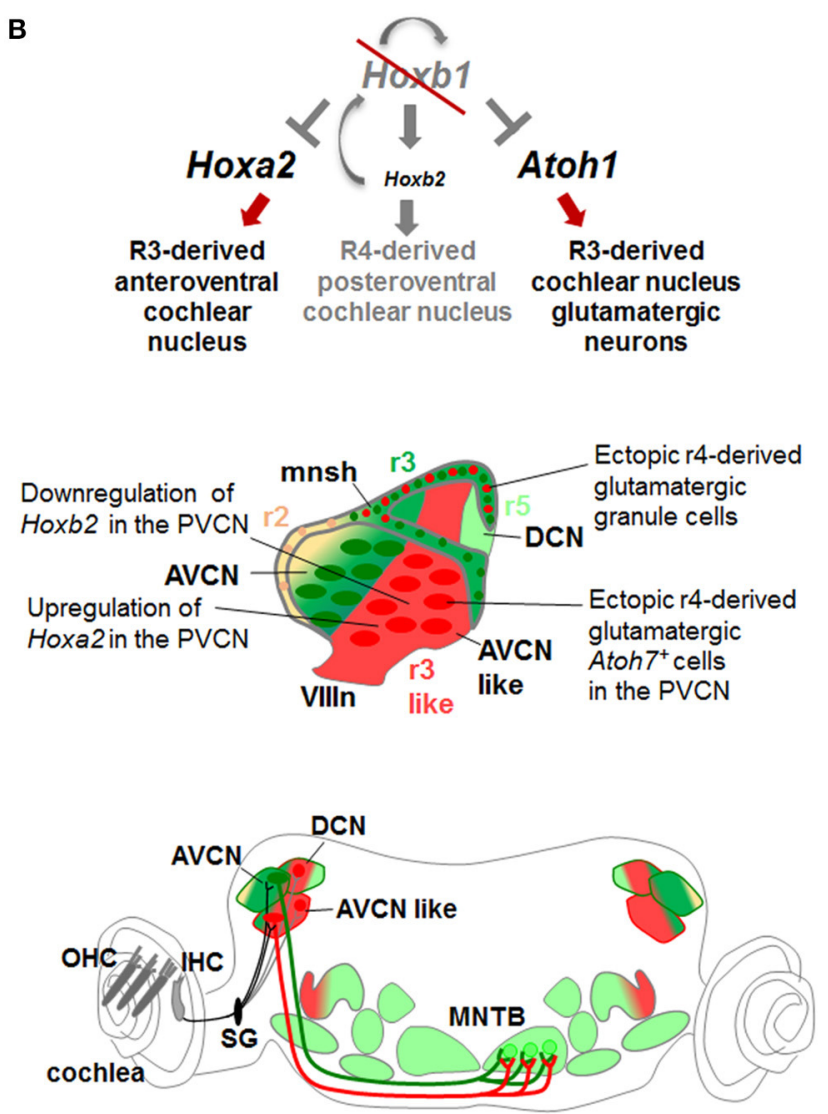

FIGURE 8 | Hox gene networks involved in the assembly of central auditory subcircuits. (A) In r4, Hoxb1 activates Hoxb2 and represses Hoxa2 and Atoh1 preventing the formation of Atoh1-derived glutamatergic neurons normally produced in $\mathrm{r} 3$. (B) In the absence of Hoxb1, Atoh1 and Hoxa2 are upregulated while Hoxb2 is downregulated at similar levels than in r3. Ectopic r4-derived granule cells contribute to the microneuronal shell. The r4-derived PVCN acquires "AVCN-like" identity producing ectopic glutamatergic Atoh $7^{+}$spherical bushy cells and projecting to the MNTB, a physiologically target of r3-derived AVCN neurons. Modified from Di Bonito et al. (2013a). 
plausible that Hoxb1 normally inhibits Atoh1 in r4, since the change of $\mathrm{r} 4$ to $\mathrm{r} 3$ identity as a result of Hoxb1 inactivation, leads to an enlargement of the $\mathrm{r} 4$ Atoh $1^{+}$sensory domain (normally smaller in $\mathrm{r} 4$ than in adjacent rhombomeres) and to ectopic production of cochlear Atoh1-derived excitatory populations (such as cochlear granule cells and $A t o h 7^{+}$neurons) (Di Bonito et al., 2013a). Overall, Hoxb1 negatively modulates Hoxa2 and Atoh1 during $\mathrm{r} 4$ patterning and thus inhibits the specification of r3-derived CN structures (Figure 8).

As previously mentioned, Ptf1a is required for the generation of inhibitory GABAergic and glycinergic neurons in the $\mathrm{CN}$ and cerebellum, whereas excitatory glutamatergic neurons derive from the Atoh1-lineage (Hoshino et al., 2005; Fujiyama et al., 2009; Yamada et al., 2014). Moreover, Ptf1a determines GABAergic over glutamatergic neuronal cell fate in the cerebellum and spinal cord (Glasgow et al., 2005; Pascual et al., 2007). In the absence of Ptf1a, neurons derived from this lineage abnormally express Atoh 1 and ectopically generate Atoh1derived glutamatergic granule cells in the cerebellum (Pascual et al., 2007). Based on this evidence, it is plausible that altered Ptfla expression might be responsible for the ectopic Atoh1 expression in dorsal $\mathrm{r} 4$ of Hoxb1 mutant mice. Thus, Ptfla may act downstream of Hoxb1 to inhibit Atoh1 and the r3-like glutamatergic fate of r4-derived cochlear neurons. Alternatively, Hoxb1 might regulate both Ptf1a and Atoh1 expression levels in sensory $\mathrm{r} 4$. Intersectional long-term fate mapping using an $\mathrm{r} 4-\mathrm{Fl} p$ line and neuronal DV subtype Cre-specific lines will be crucial to fully characterize individual $\mathrm{r} 4$ subpopulations and elucidate this aspect, as well as determine the unknown contribution of the Atoh $1^{+}$domain in $\mathrm{r} 4$.

Hoxb1 is also an important determinant gene in the r4-derived VLL development. Fate mapping analysis showed that the VLL originates from $\mathrm{r} 4$ through rostral migration. Upon loss of Hoxb1 at early stages, the majority of 4 VLL neurons are not specified leading to a strongly reduced $\mathrm{Gad}_{6} 7^{+}$GABAergic/glycinergic VLL nucleus expressing Gata3. Notably, loss of Hoxb1 at later stages (in Hoxb1 lateCKO or Hoxb2 $2^{\triangle K O}$ mutant mice) results in a less severe reduction of the VLL (Di Bonito et al., 2013a), suggesting that VLL cells start to be patterned before E9.0. Finally, VGluT2-expressing neurons in the LSO of Hoxb1 $1^{\text {null }}$ are reduced but not completely lacking, in agreement with the evidence that glutamatergic LSO neurons derive not only from r4 (Di Bonito et al., 2013a), but have also an additional contribution from r5 (Maricich et al., 2009; Marrs et al., 2013; Altieri et al., 2015).

\section{Hoxb1 Acts as a Determinant Gene of Ventral r4-Derived Motor Neurons}

Regarding the ventral $r 4$ domain, two pools of visceral motor neurons (MNv), FBM and IEE (Simon and Lumsden, 1993; Auclair et al., 1996; Bruce et al., 1997), originate from a common ventral progenitor domain expressing Nkx2.2 (pMNv) (Briscoe et al., 2000; Pattyn et al., 2003a,b) (Figure 5B). During differentiation, however, the two populations display distinct migratory behaviors. While FBM neurons migrate caudally from $\mathrm{r} 4$ to $\mathrm{r} 6$ where they form the facial nucleus of the VIIth cranial nerve (Auclair et al., 1996; Studer et al., 1996; Bruce et al., 1997), IEE neurons project contralaterally through the midline in $\mathrm{r} 4$ by somatic translocation before splitting and forming the VEN (dorsal and lateral to the internal genu of the facial nerve) and the CEN, which will give rise to the LOC and MOC neurons (respectively within and at the margin of LSO and in the medioventral part of SOC) (Simon and Lumsden, 1993; Bruce et al., 1997; Simmons, 2002; Tiveron et al., 2003; Brown and Levine, 2008; Figures 4A,C, 5A,D). Hoxb1 is required for the specification of IEE and FBM motor neurons, as demonstrated by loss- and gain-of-function studies (Goddard et al., 1996; Studer et al., 1996; Bell et al., 1999; Jungbluth et al., 1999). Hoxb1 $1^{\text {null }}$ embryos fail to specify both FBM and IEE (Goddard et al., 1996; Studer et al., 1996) and r4 motor neurons migrate dorsally acquiring a r3-derived trigeminal neuron-like migratory behavior (Studer et al., 1996). In Hoxb1 $1^{\text {lateCKO }}$ and in Hoxb2 $2^{\triangle K O}$ embryos, $\mathrm{r} 4$ ventral neurons acquire a mixed identity, whereby a portion migrate caudally following the normal migratory path of FBM (and reaching an ectopic final position in $\mathrm{r} 5$ in Hoxb1 $1^{\text {lateCKO}}$ ), while a second population follow a trigeminallike pattern of migration (Gavalas et al., 2003; Di Bonito et al., 2013a, and unpublished data). IEE-derived efferent ChAT- and Tbx20-expressing MOC and LOC neurons are lost in Hoxb $1^{\text {null }}$ mice, whereas some LOC neurons and few MOC connections are partially specified in Hoxb1 conditional mutants (Di Bonito et al., 2013a), in agreement with the timing of Hoxb1 gene inactivation. On the contrary, Hoxb1 global overexpression (Bell et al., 1999; Pata et al., 1999) or ectopic expression in r1 (Jungbluth et al., 1999) results in misspecification of neurons with identity and axonal pathfinding characteristic of $\mathrm{r} 4$ efferent neurons. This confirms that Hoxb1 is necessary and sufficient to impart an r4 motor identity in the developing hindbrain.

Besides $N k x 2.2$, the pMNv also expresses other transcription factors such as $N k x 2.9$ (Briscoe et al., 1999), $N k x 6.1$ and $N k x 6.2$ (Briscoe et al., 2000), Phox2b, Mash1 (Pattyn et al., 2000), and Gata2 (Nardelli et al., 1999; Pata et al., 1999; Tiveron et al., 2003) (Figure 5B). This domain normally produces at early stages $\mathrm{MNv}$ and at late stages serotonergic neurons along the developing hindbrain, but not in $\mathrm{r} 4$ where $\mathrm{pMNv}$ progenitors continue to form motor neurons. Intrinsic to its role as an $\mathrm{r} 4$ identity gene, Hoxb1 promotes MNv and suppresses serotonergic neuronal fate by extending the spatial and temporal activation of Phox $2 b$ expression in $N k \times 2.2^{+}$progenitors (Pattyn et al., 2003a; Jacob et al., 2007). Hoxb1 maintains Phox2b expression through direct positive regulation (Gaufo et al., 2000; Samad et al., 2004), while Phox $2 b$ inhibits Foxa2 and the serotonergic fate during sustained MNv neurogenesis in r4 (Jacob et al., 2007). Loss of $\mathrm{MNv}$ neurons and ectopic production of serotonergic neurons is therefore observed in $\mathrm{r} 4$ of both Hoxb $1^{\text {null }}$ and Phox $2 b^{\text {null }}$ mutant mice in which Foxa2 expression expands dorsally into the $N k \times 2.2^{+}$pMNv domain (Jacob et al., 2007). The initial phase of Hoxb1 expression in the $N k \times 2.2^{+}$domain in $\mathrm{r} 4$ is unaffected in $N k x 6$ ( $N k x 6.1$ and $N k x 6.2$ compound) and in Hoxb2 mutant mice until E10.5 and E11.5, respectively. Consequently, MNv generated before Hoxb1 downregulation retain $\mathrm{r} 4$ characteristics, while late-born neurons adopt a serotonergic neuronal fate, demonstrating that Hoxb1 expression 
is required over time allowing progenitors to maintain r4positional identity and to acquire their appropriate neuronal fate (Pattyn et al., 2003a).

Besides regulating Phox $2 b$ in $\mathrm{r} 4 \mathrm{pMNv}$ progenitors, Hoxb1 also induces the zinc finger transcription factor Gata2, which in turn activates its homolog Gata3 (Nardelli et al., 1999; Pata et al., 1999). Both are expressed at high levels in IEE neurons but not in FBM postmitotic neurons (Pata et al., 1999; Karis et al., 2001). By E11.5, Gata2 expression is downregulated in ventral r4, which continues to express Gata3 (Nardelli et al., 1999; Pata et al., 1999). Absence of Hoxb1 results in the loss of both Gata gene expression in $\mathrm{r} 4$ and, conversely, ubiquitous expression of Hoxbl in the hindbrain induces ectopic expression of Gata2 and Gata3 (Nardelli et al., 1999; Pata et al., 1999; Karis et al., 2001). Phox $2 b$, downstream of Hoxb1 in r4, is also required in maintaining high Gata3 expression levels in IEE neurons, since low Gata3 expression is required for serotonergic differentiation. In Phox $2 b^{\text {null }}$ embryos, IEE fail to differentiate and weak Gata3 expression is maintained in ventral serotonergic precursors throughout the length of the hindbrain including $\mathrm{r} 4$ (Tiveron et al., 2003). In Gata3 ${ }^{\text {null }}$ embryos, migration of IEE appears to happen normally, but IEE projections are reduced with only few fibers reaching the contralateral ear. In addition, the majority of OC and vestibular efferent fibers rearrange their trajectory and project along the facial and greater petrosal nerves bypassing the ear, supporting a role for Gata3 in IEE axonal pathfinding (Karis et al., 2001; Duncan et al., 2011). In summary, Hoxb1 promotes generation of ventral motor neurons by maintaining high expression levels of Phox $2 b$ (for FBM and IEE) and Gata3 (for IEE) in ventral $\mathrm{r} 4$ and repressing thus a r3-like serotonergic fate.

\section{Interactions between Efferent Neurons and Hair Cells during Cochlear Functional Maturation}

In the absence or aberrant differentiation of IEE, as observed in Hoxb1 mutant embryos, OHCs degenerate mainly in the apical cochlear portion, causing the altered hearing threshold described in adult mice (Di Bonito et al., 2013a). In particular, the transmission of low-level auditory stimuli is strongly affected resulting in severe hearing impairments. One hypothesis is that $\mathrm{OHC}$ degeneration might be caused by the absence of synaptic/trophic innervation from efferent OC fibers during a postnatal critical period, shown to be important for proper OHC maturation (Walsh et al., 1998; Di Bonito et al., 2013a). This is mainly supported by the observation that in Hoxb1 $1^{\text {null }}$ mutants OHC morphology is not affected until early postnatal stages, but impaired only after synaptic MOC/OHC interactions normally occur, which instead fail to be formed in the absence of MOC neurons. Moreover, the persistence of some MOC neurons innervating OHCs in Hoxbl lateCKO and $H o x b 2^{\triangle K O}$ mutants, in which Hoxb1 is not fully abolished, correlates with milder OHC morphological and hearing threshold defects (Di Bonito et al., 2013a). The importance of early interactions between efferent neurons and their postsynaptic targets for proper cochlear functional maturation had been previously suggested by deefferentation studies in the cats. Surgical physical deefferentation in neonatal cats, but not in adult cats, resulted in threshold elevations and other cochlear response abnormalities consistent with OHC dysfunctions (Walsh et al., 1998). However, in the absence of $\mathrm{OHC}$ nicotinic acetylcholine receptor subunits $\alpha 9$ (Vetter et al., 1999; Brown and Vetter, 2009) or $\alpha 10$ (Vetter et al., 2007), the MOC/OHC efferent innervation is still preserved even if terminals contacting $\mathrm{OHC}$ are abnormal in size and numbers. Surprisingly, even if the MOC inhibition on $\mathrm{OHC}$ activity cannot be transduced (due to the lack of these receptors) leading thus to a complete "functional deefferentation," the cochlear response is maintained with no abnormalities in ABR thresholds or DPOAE amplitudes (Vetter et al., 1999, 2007). This is different from the surgical physical deefferentation described above, since OHCs seem to function normally despite the inability of OHCs to respond to the MOC inhibition. However, in these mutants where the MOC innervation is still maintained, only one of the two $\alpha$-nicotinic receptor subunits is eliminated, while several other synaptic proteins are preserved at the MOC/OHC synapse, whose contribution could compensate. It is thus premature to conclude that the lack of a significant developmental effect and the apparent normal cochlear responses in the acetylcholine receptors mutant mice contradict the influence of efferent terminals on the functional $\mathrm{OHC}$ maturation. Alternatively, the action of the efferent system on the functional development of OHCs might be mediated by a process not involving $\alpha 9$ - and $\alpha 10$-nicotinic receptors (Vetter et al., 1999; Simmons, 2002). Future genetic, such as double $\alpha 9 / \alpha 10 \mathrm{KOs}$, and sophisticated functional studies might further clarify this issue.

Altered development of auditory sensory structures might also contribute to the hearing phenotype of Hoxb $1^{\text {null }}$ mice. Even if this possibility cannot be completely ruled out, the persistence of few MOC neurons in some Hoxb $1^{\text {lateCKO }}$ mutant mice correlates well with less severe OHC morphology and threshold impairments, although other auditory sensory nuclei are similarly affected in all conditional mutants (Di Bonito et al., 2013a and unpublished data). This strongly suggests that early interactions between OC and OHC might be crucial for proper maturation of hair cells. Thus, to ultimately discern between these possibilities, Hoxbl should be inactivated either in the sensory or only in the motor r4-derived components of the auditory pathway. Finally, the progressively more drastic increase of auditory threshold with age observed in Hoxb1 adult mutant mice is likely due to the reduced function of efferent (MOC and MEM) reflexes, as well as LOC neurons, which cannot protect the organ of Corti from noise-induced hearing damages. Accordingly, Hoxb1 conditional mice, whose efferent neurons (MOC, LOC, and FBM) are partially preserved have a less severe increase of auditory threshold with age compared to Hoxb1 $1^{\text {null }}$ mice in which all efferent motor neurons are completely absent (Di Bonito et al., 2013a).

A similar hearing loss phenotype due to degeneration of OHCs with consequent increase of auditory threshold has also been described in heterozygous Gata3 mutant mice, a model of GATA3 haploinsufficiency that causes the human autosomal dominant HDR (Hypoparathyroidism, Deafness and 
Renal dysplasia) syndrome (Bilous et al., 1992; Van Esch et al., 2000; van der Wees et al., 2004). In particular, the hearing threshold elevation of $30 \mathrm{~dB}$ and reduction of $\mathrm{OHC}$ functionality in heterozygous Gata3 mice seem to be caused by the progressive morphological degeneration of OHCs at the apex followed by progressive degeneration of all hair cells and supporting cells in the entire cochlea (van der Wees et al., 2004; van Looij et al., 2005). Gata3 is continuously expressed from early development to adulthood in different parts of both the inner ear and the central auditory nervous system. Indeed, Gata3 is expressed in the SG neurons and in virtually all cell types of the inner ear including IHCs, OHCs and supporting cells (Karis et al., 2001; Lawoko-Kerali et al., 2002) and plays a crucial role in the inner ear neurosensory cochlear development, as demonstrated by constitutive and conditional KO studies (Haugas et al., 2012; Appler et al., 2013; Duncan and Fritzsch, 2013; Luo et al., 2013). In the central auditory system, Gata3 is found in the SPO, VLL, IC, and IEE efferent neurons (Karis et al., 2001; van der Wees et al., 2004; Di Bonito et al., 2013a). Since it is also expressed in the OHCs, it is highly probable that reduced levels of Gata3 within the cochlea might be the major cause of hearing impairments. However, Gata3 is also involved in driving IEE fibers to the ear. Thus, it is also plausible that absence of innervation of OHCs by OC neurons might contribute to the hearing loss caused by GATA3 haploinsufficiency in the human HDR syndrome. Conditional and intersectional deletion studies inactivating Gata3 either in the CNS or in the inner ear will be useful to dissect the central and peripheral functional roles of Gata3 during formation of the auditory system.

\section{Hoxb2 Expression Is Maintained in r3- To r5-Derived Auditory Nuclei}

Hoxb2 acts in maintaining high expression of Hoxb1 in r4 progenitors since Hoxb1 expression is initiated but not maintained in $\mathrm{r} 4$ of Hoxb2 mutants (Barrow and Capecchi, 1996; Gavalas et al., 2003; Pattyn et al., 2003a; Di Bonito et al., 2013a) and Hoxb2 ${ }^{\triangle K O}$ mice reproduce similar phenotypes as Hoxb1 $1^{\text {lateCKO }}$ mice, in which only late expression of Hoxb1 is eliminated (Di Bonito et al., 2013a). Moreover, Hoxb2 is a direct target activated by Hoxb1 in $\mathrm{r} 4$ progenitors (Maconochie et al., 1997; Ferretti et al., 2000) and, importantly, is maintained in r4-derived auditory nuclei, such as the VLL and PVCN (Narita and Rijli, 2009; Di Bonito et al., 2013a), suggesting that Hoxb2 plays a role in relaying r4-dependent regional fate to postmitotic neurons. Moreover, Hoxb2 is also expressed in r3 and r5 together with Hoxa2 and maintained in r3-derived granule cells and AVCN (Di Bonito et al., 2013a) and in r5-derived SOC nuclei (Narita and Rijli, 2009). A transgenic line activating the Cre recombinase under the control of a Hoxb2 r4 enhancer crossed with a R26R LacZ reporter shows labeling in the early otocyst, in the vestibular and spiral ganglia, and in all otic epithelia at later stages (Szeto et al., 2009). Thus conditional inactivation of Hoxb2 after E13.5, when Hoxb1 expression is downregulated in $\mathrm{r} 4$, or specifically in $\mathrm{r} 3$ and/or $\mathrm{r} 5$ would help in unraveling Hoxb2 specific roles in auditory central nuclei. In addition, the use of the b2-r4-Cre transgenic mice (Szeto et al., 2009) might provide an important tool for conditional gene ablation and lineage tracing in the inner ear.

\section{Hoxa2 Is an Important Determinant Gene of r2/r3-Derived Anterior Cochlear Nucleus}

Inactivation of Hoxa2 results in lethality at birth and in a homeotic transformation of structures derived from the 2 nd arch neural crest into 1st arch derivatives (Gendron-Maguire et al., 1993; Rijli et al., 1993). As a result, Hoxa $2^{\text {null }}$ mutants exhibit defects in the formation of the middle and external ears: in the middle ear, the stapes and stapedius muscles (2nd pharyngeal arch neural crest derivatives) are lost with a duplication of the malleus and incus primordia and enlargement of the muscles of the malleus, the tensor tympani (1st pharyngeal arc neural crest derivatives). In the hindbrain, Hoxa2, strongly expressed in $\mathrm{r} 3$ and at lower levels in $\mathrm{r} 2$, plays a key role in the segmental identity of these rhombomeres and is required in patterning the r2/r3-derived AVCN (Gavalas et al., 1997; Farago et al., 2006). Loss of Hoxa2 mainly impairs the development of the AVCN, which is drastically reduced in Hoxa $2^{\text {null }}$ mice, and the respective projections to the contralateral MNTB nucleus as described in Hoxa2 conditional mutant mice (Gavalas et al., 1997; Di Bonito et al., 2013a). In the AVCN, Hoxa2 controls expression of the Slit receptor Rig1/Robo3 (Di Bonito et al., 2013a), known to regulate midline crossing of commissural axons in the hindbrain (Renier et al., 2010). Early conditional Hoxa2 inactivation in rhombic-lip derivatives selectively affects Rig1 expression and AVCN axonal pathfinding to MNTB, resulting in reduced contralateral and ectopic ipsilateral fibers targeting the MNTB (Di Bonito et al., 2013a). It is unlikely that the Hoxa2-mediated regulation of Rig1 alone could explain the PVCN-to-AVCN target connectivity switch observed in Hoxb1 and Hoxb2 mutant mice, since Rig1 only confers the ability of axons to cross the midline. Most probably, Hoxa2 acts as an important determinant of a larger transcriptional program required to specify $\mathrm{r} 2 / \mathrm{r} 3$-derived AVCN neurons with their proper identity and connectivity. Even if the domain of Atoh7 expression is reduced in the smaller AVCN of Hoxa $2^{\text {null }}$ embryos, Atoh 7 continues to be expressed in the residual CN cells indicating that Atoh7 is not under the transcriptional control of Hoxa2 (Di Bonito et al., 2013a). Hoxa2 and Atoh7, which is downstream of Atoh1, could be part of two parallel pathways essential for AVCN formation, identity and connectivity. Both pathways may be specific for $\mathrm{r} 3$ and normally downregulated in $\mathrm{r} 4$ by Hoxb1-mediated inhibition of Hoxa2 and Atoh1 (Figure 8). A new role of Hoxa2 in the AVCN has been recently reported. Hox 2 genes are required for the proper innervation of Atoh1-derived glutamatergic bushy cells by SG afferent neurons and sound-frequency discrimination, indicating a role for these Hox factors in tonotopic refinement of connectivity and in ensuring the precision of sound transmission in the mammalian auditory circuit (Karmakar et al., 2017).

Differently from the AVCN, Hoxa2 do not appear to play a predominant role in VLL specification since no size abnormalities have been observed in the VLL during 
development (Di Bonito et al., 2013a). However, we cannot exclude that Hoxa2 might be involved in axonal pathfinding of VLL neurons similar to what described for the AVCN (Di Bonito et al., 2013a) and for the principal trigeminal sensory PrV (Oury et al., 2006) nuclei. The role of Hoxa2 in the SOC remains to be elucidated.

\section{CONCLUSIONS AND PERSPECTIVES}

Thanks to the availability of several mouse transgenic lines, significant progress in the identification and formation of auditory sensorimotor hindbrain subcircuits has been obtained in the last few years. It is now well accepted in the field that rostral rhombomeres and their associated Hox genes are involved in establishing and maintaining two major functional circuits in the central auditory system. Hoxb1 and Hoxb2 appear to act primarily in the assembly of $\mathrm{r} 4$-derived structures by contributing to the main sound transmission pathway, as well as in the establishment of sensorimotor reflex circuits important for the cochlear amplification and protection (Figure 6). Hoxa2 instead seems to contribute to AVCN development and connectivity in the sound localization circuitry mainly formed by r2, r3, and r5 (Figure 7).

Despite the considerable progress made in the field, we still need to understand the exact origin, cellular behavior (tangential vs. radial migration), connectivity patterns and molecular profile of several auditory neuronal populations. The intersectional strategy using both Cre- and Flp-recombinase mouse lines together with a dual reporter transgenic line will increase the opportunity to label, mutate and isolate restricted hindbrain subpopulations, and thus represents an important tool for future studies (Dymecki et al., 2010). By intersectional lineage tracing, distinct rhombomere-specific DV subdomains contributing to several auditory nuclei and subcircuits can be identified and labeled, and single

\section{REFERENCES}

Alasti, F., Sadeghi, A., Sanati, M. H., Farhadi, M., Stollar, E., Somers, T., et al. (2008). A mutation in HOXA2 is responsible for autosomalrecessive microtia in an Iranian family. Am. J. Hum. Genet. 82, 982-991. doi: 10.1016/j.ajhg.2008.02.015

Alaynick, W. A., Jessell, T. M., and Pfaff, S. L. (2011). SnapShot: spinal cord development. Cell 146, 178-178 e171. doi: 10.1016/j.cell.2011.06.038

Altieri, S. C., Jalabi, W., Zhao, T., Romito-DiGiacomo, R. R., and Maricich, S. M. (2015). En1 directs superior olivary complex neuron positioning, survival, and expression of FoxP1. Dev. Biol. 408, 99-108. doi: 10.1016/j.ydbio.2015.10.008

Altieri, S. C., Zhao, T., Jalabi, W., and Maricich, S. M. (2014). Development of glycinergic innervation to the murine LSO and SPN in the presence and absence of the MNTB. Front. Neural Circuits 8:109. doi: 10.3389/fncir.2014.00109

Altieri, S. C., Zhao, T., Jalabi, W., Romito-DiGiacomo, R. R., and Maricich, S. M. (2016). En1 is necessary for survival of neurons in the ventral nuclei of the lateral lemniscus. Dev. Neurobiol. 76, 1266-1274. doi: 10.1002/dneu.22388

Anthwal, N., and Thompson, H. (2016). The development of the mammalian outer and middle ear. J. Anat. 228, 217-232. doi: 10.1111/joa.12344

Appler, J. M., Lu, C. C., Druckenbrod, N. R., Yu, W. M., Koundakjian, E. J., and Goodrich, L. V. (2013). Gata3 is a critical regulator of cochlear wiring. J. Neurosci. 33, 3679-3691. doi: 10.1523/JNEUROSCI.4703-12.2013 neuronal populations can be traced from embryonic stages to adulthood. The comparison of mutant backgrounds will unravel how different subdomains and neuronal derivatives contribute to the normal and diseased acoustic pathways and allow identification of their functional role. Moreover, the intersectional fate mapping will be helpful in dissecting rhombomere-specific molecular auditory pathways of single DV subdomains and deciphering how correspondent domains of different rhombomeres can contribute to distinct auditory neurons with different functions. In mouse models of hearing impairments, the intersectional strategy could be used to isolate selected neuronal subpopulations and identify, through genomic approaches, novel molecular players that are involved in the specification and circuit assembly of auditory neuronal subtypes, and eventually affected in hearing loss pathologies of mice and humans. The identification of the molecular, anatomical and functional properties of distinct auditory neuronal populations in normal and pathological conditions will help in unraveling the genetic causes of deafness and characterizing novel genes involved in hearing. This will allow designing novel molecular genetic tests for hearing diagnosis and genetic counseling, and provide basic knowledge for clinical research of future therapies.

\section{AUTHOR CONTRIBUTIONS}

All authors listed, have made substantial, direct and intellectual contribution to the work, and approved it for publication.

\section{ACKNOWLEDGMENTS}

This work was supported by the French "Agence National de la Recherche" (ANR) "2009 Chaire d'Excellence" \#R09125AA and “DEAF” \#ANR-15-CE15-0016-01 Programs to MS.
Arenkiel, B. R., Gaufo, G. O., and Capecchi, M. R. (2003). Hoxb1 neural crest preferentially form glia of the PNS. Dev. Dyn. 227, 379-386. doi: 10.1002/dvdy.10323

Aroca, P., and Puelles, L. (2005). Postulated boundaries and differential fate in the developing rostral hindbrain. Brain Res. Brain Res. Rev. 49, 179-190. doi: 10.1016/j.brainresrev.2004.12.031

Ashmore, J., Avan, P., Brownell, W. E., Dallos, P., Dierkes, K., Fettiplace, R., et al. (2010). The remarkable cochlear amplifier. Hear. Res. 266, 1-17. doi: 10.1016/j.heares.2010.05.001

Auclair, F., Valdes, N., and Marchand, R. (1996). Rhombomere-specific origin of branchial and visceral motoneurons of the facial nerve in the rat embryo. J. Comp. Neurol. 369, 451-461. doi: 10.1002/(SICI)1096-9861(19960603)369:3< 451::AID-CNE9>3.0.CO;2-4

Awatramani, R., Soriano, P., Rodriguez, C., Mai, J. J., and Dymecki, S. M. (2003). Cryptic boundaries in roof plate and choroid plexus identified by intersectional gene activation. Nat. Genet. 35, 70-75. doi: 10.1038/ng1228

Barrow, J. R., and Capecchi, M. R. (1996). Targeted disruption of the Hoxb-2 locus in mice interferes with expression of Hoxb-1 and Hoxb-4. Development 122, 3817-3828

Bell, E., Wingate, R. J., and Lumsden, A. (1999). Homeotic transformation of rhombomere identity after localized Hoxb1 misexpression. Science 284, $2168-2171$ 
Bermingham, N. A., Hassan, B. A., Price, S. D., Vollrath, M. A., Ben-Arie, N., Eatock, R. A., et al. (1999). Math1: an essential gene for the generation of inner ear hair cells. Science 284, 1837-1841.

Bilous, R. W., Murty, G., Parkinson, D. B., Thakker, R. V., Coulthard, M. G., Burn, J., et al. (1992). Brief report: autosomal dominant familial hypoparathyroidism, sensorineural deafness, and renal dysplasia. N. Engl. J. Med. 327, 1069-1074. doi: 10.1056/NEJM199210083271506

Bosley, T. M., Alorainy, I. A., Salih, M. A., Aldhalaan, H. M., Abu-Amero, K. K., Oystreck, D. T., et al. (2008). The clinical spectrum of homozygous HOXA1 mutations. Am. J. Med. Genet. A. 146A, 1235-1240. doi: 10.1002/ajmg.a. 32262

Briscoe, J., Pierani, A., Jessell, T. M., and Ericson, J. (2000). A homeodomain protein code specifies progenitor cell identity and neuronal fate in the ventral neural tube. Cell 101, 435-445. doi: 10.1016/S0092-8674(00)80853-3

Briscoe, J., Sussel, L., Serup, P., Hartigan-O’Connor, D., Jessell, T. M., Rubenstein, J. L., et al. (1999). Homeobox gene Nkx2.2 and specification of neuronal identity by graded Sonic hedgehog signalling. Nature 398, 622-627.

Brown, K. K., Viana, L. M., Helwig, C. C., Artunduaga, M. A., QuintanillaDieck, L., Jarrin, P., et al. (2013). HOXA2 haploinsufficiency in dominant bilateral microtia and hearing loss. Hum. Mutat. 34, 1347-1351. doi: 10.1002/humu.22367

Brown, M. C., and Levine, J. L. (2008). Dendrites of medial olivocochlear neurons in mouse. Neuroscience 154, 147-159. doi: 10.1016/j.neuroscience.2007.12.045

Brown, M. C., and Vetter, D. E. (2009). Olivocochlear neuron central anatomy is normal in alpha 9 knockout mice. J. Assoc. Res. Otolaryngol. 10, 64-75. doi: 10.1007/s10162-008-0144-9

Brown, M. C., de Venecia, R. K., and Guinan, J. J. Jr. (2003). Responses of medial olivocochlear neurons. Specifying the central pathways of the medial olivocochlear reflex. Exp. Brain Res. 153, 491-498. doi: 10.1007/s00221-003-1679-y

Bruce, L. L., Kingsley, J., Nichols, D. H., and Fritzsch, B. (1997). The development of vestibulocochlear efferents and cochlear afferents in mice. Int. J. Dev. Neurosci. 15, 671-692. doi: 10.1016/S0736-5748(96)00120-7

Cai, X., Kardon, A. P., Snyder, L. M., Kuzirian, M. S., Minestro, S., de Souza, L., et al. (2016). Bhlhb5::flpo allele uncovers a requirement for Bhlhb5 for the development of the dorsal cochlear nucleus. Dev. Biol. 414, 149-160. doi: 10.1016/j.ydbio.2016.04.028

Cambronero, F., and Puelles, L. (2000). Rostrocaudal nuclear relationships in the avian medulla oblongata: a fate map with quail chick chimeras. J. Comp. Neurol. 427, 522-545. doi: 10.1002/1096-9861(20001127)427:4<522::AID-CNE3> 3.0.CO;2-Y

Cant, N. B., and Benson, C. G. (2003). Parallel auditory pathways: projection patterns of the different neuronal populations in the dorsal and ventral cochlear nuclei. Brain Res. Bull. 60, 457-474. doi: 10.1016/S0361-9230(03) 00050-9

Carpenter, E. M., Goddard, J. M., Chisaka, O., Manley, N. R., and Capecchi, M. R. (1993). Loss of Hox-A1 (Hox-1.6) function results in the reorganization of the murine hindbrain. Development 118, 1063-1075.

Chambers, D., Wilson, L. J., Alfonsi, F., Hunter, E., Saxena, U., Blanc, E., et al. (2009). Rhombomere-specific analysis reveals the repertoire of genetic cues expressed across the developing hindbrain. Neural Dev. 4:6. doi: 10.1186/1749-8104-4-6

Chen, Y., Takano-Maruyama, M., Fritzsch, B., and Gaufo, G. O. (2012). Hoxb1 controls anteroposterior identity of vestibular projection neurons. PLoS ONE 7:e34762. doi: 10.1371/journal.pone.0034762

Chisaka, O., Musci, T. S., and Capecchi, M. R. (1992). Developmental defects of the ear, cranial nerves and hindbrain resulting from targeted disruption of the mouse homeobox gene Hox-1.6. Nature 355, 516-520.

Cramer, K. S., Fraser, S. E., and Rubel, E. W. (2000). Embryonic origins of auditory brain-stem nuclei in the chick hindbrain. Dev. Biol. 224, 138-151. doi: 10.1006/dbio.2000.9779

Darrow, K. N., Benson, T. E., and Brown, M. C. (2012). Planar multipolar cells in the cochlear nucleus project to medial olivocochlear neurons in mouse. J. Comp. Neurol. 520, 1365-1375. doi: 10.1002/cne.22797

Darrow, K. N., Maison, S. F., and Liberman, M. C. (2007). Selective removal of lateral olivocochlear efferents increases vulnerability to acute acoustic injury. J. Neurophysiol. 97, 1775-1785. doi: 10.1152/jn.00955.2006
Davenne, M., Maconochie, M. K., Neun, R., Pattyn, A., Chambon, P., Krumlauf, R., et al. (1999). Hoxa2 and Hoxb2 control dorsoventral patterns of neuronal development in the rostral hindbrain. Neuron 22, 677-691. doi: 10.1016/S0896-6273(00)80728-X

de Venecia, R. K., Liberman, M. C., Guinan, J. J. Jr., and Brown, M. C. (2005). Medial olivocochlear reflex interneurons are located in the posteroventral cochlear nucleus: a kainic acid lesion study in guinea pigs. J. Comp. Neurol. 487, 345-360. doi: 10.1002/cne.20550

Diaz, C., Puelles, L., Marin, F., and Glover, J. C. (1998). The relationship between rhombomeres and vestibular neuron populations as assessed in quail-chicken chimeras. Dev. Biol. 202, 14-28. doi: 10.1006/dbio.1998.8986

Di Bonito, M., Boulland, J. L., Krezel, W., Setti, E., Studer, M., and Glover, J. C. (2015). Loss of projections, functional compensation, and residual deficits in the mammalian vestibulospinal system of hoxb1-deficient mice. eNeuro 2. doi: 10.1523/eneuro.0096-15.2015

Di Bonito, M., Glover, J. C., and Studer, M. (2013b). Hox genes and region-specific sensorimotor circuit formation in the hindbrain and spinal cord. Dev. Dyn. 242, 1348-1368. doi: 10.1002/dvdy.24055

Di Bonito, M., Narita, Y., Avallone, B., Sequino, L., Mancuso, M., Andolfi, G., et al. (2013a). Assembly of the auditory circuitry by a Hox genetic network in the mouse brainstem. PLoS Genet. 9:e1003249. doi: 10.1371/journal.pgen.10 03249

Di Meglio, T., Kratochwil, C. F., Vilain, N., Loche, A., Vitobello, A., Yonehara, K., et al. (2013). Ezh2 orchestrates topographic migration and connectivity of mouse precerebellar neurons. Science 339, 204-207. doi: $10.1126 /$ science. 1229326

Dolle, P., Lufkin, T., Krumlauf, R., Mark, M., Duboule, D., and Chambon, P. (1993). Local alterations of Krox-20 and Hox gene expression in the hindbrain suggest lack of rhombomeres 4 and 5 in homozygote null Hoxa1 (Hox-1.6) mutant embryos. Proc. Natl. Acad. Sci. U.S.A. 90, 7666-7670. doi: 10.1073 /pnas.90.16.7666

Duboule, D., and Dolle, P. (1989). The structural and functional organization of the murine HOX gene family resembles that of Drosophila homeotic genes. EMBO J. 8, 1497-1505.

Duncan, J. S., and Fritzsch, B. (2013). Continued expression of GATA3 is necessary for cochlear neurosensory development. PLoS ONE 8:e62046. doi: 10.1371/journal.pone.0062046

Duncan, J. S., Lim, K. C., Engel, J. D., and Fritzsch, B. (2011). Limited inner ear morphogenesis and neurosensory development are possible in the absence of GATA3. Int. J. Dev. Biol. 55, 297-303. doi: 10.1387/ijdb.103178jd

Dupe, V., Davenne, M., Brocard, J., Dolle, P., Mark, M., Dierich, A., et al. (1997). In vivo functional analysis of the Hoxa-1 3' retinoic acid response element (3'RARE). Development 124, 399-410.

Dymecki, S. M., Ray, R. S., and Kim, J. C. (2010). Mapping cell fate and function using recombinase-based intersectional strategies. Methods Enzymol. 477, 183-213. doi: 10.1016/S0076-6879(10)77011-7

Farago, A. F., Awatramani, R. B., and Dymecki, S. M. (2006). Assembly of the brainstem cochlear nuclear complex is revealed by intersectional and subtractive genetic fate maps. Neuron 50, 205-218. doi: 10.1016/j.neuron.2006.03.014

Ferretti, E., Marshall, H., Popperl, H., Maconochie, M., Krumlauf, R., and Blasi, F. (2000). Segmental expression of Hoxb2 in r4 requires two separate sites that integrate cooperative interactions between Prep1, Pbx and Hox proteins. Development 127, 155-166.

Fraser, S., Keynes, R., and Lumsden, A. (1990). Segmentation in the chick embryo hindbrain is defined by cell lineage restrictions. Nature 344, 431-435.

Fujiyama, T., Yamada, M., Terao, M., Terashima, T., Hioki, H., Inoue, Y. U., et al. (2009). Inhibitory and excitatory subtypes of cochlear nucleus neurons are defined by distinct bHLH transcription factors, Ptfla and Atoh1. Development 136, 2049-2058. doi: 10.1242/dev.033480

Gaufo, G. O., Flodby, P., and Capecchi, M. R. (2000). Hoxb1 controls effectors of sonic hedgehog and Mash1 signaling pathways. Development 127, 5343-5354.

Gaufo, G. O., Thomas, K. R., and Capecchi, M. R. (2003). Hox3 genes coordinate mechanisms of genetic suppression and activation in the generation of branchial and somatic motoneurons. Development 130, 5191-5201. doi: 10.1242/dev.00730 
Gaufo, G. O., Wu, S., and Capecchi, M. R. (2004). Contribution of Hox genes to the diversity of the hindbrain sensory system. Development 131, 1259-1266. doi: $10.1242 /$ dev.01029

Gavalas, A., Davenne, M., Lumsden, A., Chambon, P., and Rijli, F. M. (1997). Role of Hoxa-2 in axon pathfinding and rostral hindbrain patterning. Development 124, 3693-3702.

Gavalas, A., Ruhrberg, C., Livet, J., Henderson, C. E., and Krumlauf, R. (2003). Neuronal defects in the hindbrain of Hoxa1, Hoxb1 and Hoxb2 mutants reflect regulatory interactions among these Hox genes. Development 130, 5663-5679. doi: $10.1242 /$ dev.00802

Geisen, M. J., Di Meglio, T., Pasqualetti, M., Ducret, S., Brunet, J. F., Chedotal, A., et al. (2008). Hox paralog group 2 genes control the migration of mouse pontine neurons through slit-robo signaling. PLoS Biol. 6:e142. doi: 10.1371/journal.pbio.0060142

Gendron-Maguire, M., Mallo, M., Zhang, M., and Gridley, T. (1993). Hoxa-2 mutant mice exhibit homeotic transformation of skeletal elements derived from cranial neural crest. Cell 75, 1317-1331. doi: 10.1016/0092-8674(93)90619-2

Glasgow, S. M., Henke, R. M., Macdonald, R. J., Wright, C. V., and Johnson, J. E. (2005). Ptfla determines GABAergic over glutamatergic neuronal cell fate in the spinal cord dorsal horn. Development 132, 5461-5469. doi: $10.1242 /$ dev. 02167

Goddard, J. M., Rossel, M., Manley, N. R., and Capecchi, M. R. (1996). Mice with targeted disruption of Hoxb-1 fail to form the motor nucleus of the VIIth nerve. Development 122, 3217-3228.

Goutman, J. D., Elgoyhen, A. B., and Gomez-Casati, M. E. (2015). Cochlear hair cells: the sound-sensing machines. FEBS Lett. 589, 3354-3361. doi: 10.1016/j.febslet.2015.08.030

Graham, A., Papalopulu, N., and Krumlauf, R. (1989). The murine and Drosophila homeobox gene complexes have common features of organization and expression. Cell 57, 367-378. doi: 10.1016/0092-8674(89)90912-4

Gray, P. A. (2008). Transcription factors and the genetic organization of brain stem respiratory neurons. J. Appl. Physiol. (1985). 104, 1513-1521. doi: 10.1152/japplphysiol.01383.2007

Gray, P. A. (2013). Transcription factors define the neuroanatomical organization of the medullary reticular formation. Front. Neuroanat. 7:7. doi: $10.3389 /$ fnana.2013.00007

Grothe, B., Pecka, M., and McAlpine, D. (2010). Mechanisms of sound localization in mammals. Physiol. Rev. 90, 983-1012. doi: 10.1152/physrev.00026.2009

Guinan, J. J. Jr. (2006). Olivocochlear efferents: anatomy, physiology, function, and the measurement of efferent effects in humans. Ear Hear. 27, 589-607. doi: 10.1097/01.aud.0000240507.83072.e7

Guinan, J. J. Jr. (2013). New insights into cochlear amplification. Biophys. J. 105, 839-840. doi: 10.1016/j.bpj.2013.07.016

Guthrie, S. (2007). Patterning and axon guidance of cranial motor neurons. Nat. Rev. Neurosci. 8, 859-871. doi: 10.1038/ nrn2254

Guthrie, S., Butcher, M., and Lumsden, A. (1991). Patterns of cell division and interkinetic nuclear migration in the chick embryo hindbrain. J. Neurobiol. 22, 742-754. doi: 10.1002/neu.480220709

Haugas, M., Lillevali, K., and Salminen, M. (2012). Defects in sensory organ morphogenesis and generation of cochlear hair cells in Gata3-deficient mouse embryos. Hear. Res. 283, 151-161. doi: 10.1016/j.heares.2011.10.010

Heyman, I., Faissner, A., and Lumsden, A. (1995). Cell and matrix specialisations of rhombomere boundaries. Dev. Dyn. 204, 301-315. doi: 10.1002/aja.1002040308

Hoshino, M., Nakamura, S., Mori, K., Kawauchi, T., Terao, M., Nishimura, Y. V., et al. (2005). Ptfla, a bHLH transcriptional gene, defines GABAergic neuronal fates in cerebellum. Neuron 47, 201-213. doi: 10.1016/j.neuron.2005. 06.007

Hufnagel, R. B., Riesenberg, A. N., Saul, S. M., and Brown, N. L. (2007). Conserved regulation of Math5 and Math1 revealed by Math5-GFP transgenes. Mol. Cell. Neurosci. 36, 435-448. doi: 10.1016/j.mcn.2007.08.006

Hunt, P., Gulisano, M., Cook, M., Sham, M. H., Faiella, A., Wilkinson, D., et al. (1991). A distinct Hox code for the branchial region of the vertebrate head. Nature 353, 861-864.

Ito, T., Bishop, D. C., and Oliver, D. L. (2011). Expression of glutamate and inhibitory amino acid vesicular transporters in the rodent auditory brainstem. J. Comp. Neurol. 519, 316-340. doi: 10.1002/cne.22521
Jacob, J., Ferri, A. L., Milton, C., Prin, F., Pla, P., Lin, W., et al. (2007). Transcriptional repression coordinates the temporal switch from motor to serotonergic neurogenesis. Nat. Neurosci. 10, 1433-1439. doi: 10.1038/nn1985

Jalabi, W., Kopp-Scheinpflug, C., Allen, P. D., Schiavon, E., DiGiacomo, R. R., Forsythe, I. D., et al. (2013). Sound localization ability and glycinergic innervation of the superior olivary complex persist after genetic deletion of the medial nucleus of the trapezoid body. J. Neurosci. 33, 15044-15049. doi: 10.1523/JNEUROSCI.2604-13.2013

Jessell, T. M. (2000). Neuronal specification in the spinal cord: inductive signals and transcriptional codes. Nat. Rev. Genet. 1, 20-29. doi: 10.1038/3504 9541

Jimenez-Guri, E., Udina, F., Colas, J. F., Sharpe, J., Padron-Barthe, L., Torres, M., et al. (2010). Clonal analysis in mice underlines the importance of rhombomeric boundaries in cell movement restriction during hindbrain segmentation. PLoS ONE 5:e10112. doi: 10.1371/journal.pone.0010112

Jungbluth, S., Bell, E., and Lumsden, A. (1999). Specification of distinct motor neuron identities by the singular activities of individual Hox genes. Development 126, 2751-2758.

Kandler, K., and Gillespie, D. C. (2005). Developmental refinement of inhibitory sound-localization circuits. Trends Neurosci. 28, 290-296. doi: 10.1016/j.tins.2005.04.007

Karis, A., Pata, I., van Doorninck, J. H., Grosveld, F., de Zeeuw, C. I., de Caprona, D., et al. (2001). Transcription factor GATA3 alters pathway selection of olivocochlear neurons and affects morphogenesis of the ear. J. Comp. Neurol. 429, 615-630. doi: 10.1002/1096-9861(20010122)429:4<615::AID-CNE8>3.0.CO;2-F

Karmakar, K., Narita, Y., Fadok, J., Ducret, S., Loche, A., Kitazawa, T., et al. (2017). Hox 2 genes are required for tonotopic map precision and sound discrimination in the mouse auditory brainstem. Cell Rep. 18, 185-197. doi: 10.1016/j.celrep.2016.12.021

Kranz, A., Fu, J., Duerschke, K., Weidlich, S., Naumann, R., Stewart, A. F., et al. (2010). An improved Flp deleter mouse in $\mathrm{C} 57 \mathrm{Bl} / 6$ based on Flpo recombinase. Genesis 48, 512-520. doi: 10.1002/dvg.20641

Krumlauf, R. (1993a). Hox genes and pattern formation in the branchial region of the vertebrate head. Trends Genet. 9, 106-112.

Krumlauf, R. (1993b). Mouse Hox genetic functions. Curr. Opin. Genet. Dev. 3, $621-625$.

Krumlauf, R., Marshall, H., Studer, M., Nonchev, S., Sham, M. H., and Lumsden, A. (1993). Hox homeobox genes and regionalisation of the nervous system. J. Neurobiol. 24, 1328-1340. doi: 10.1002/neu.480241006

Kujawa, S. G., and Liberman, M. C. (1997). Conditioning-related protection from acoustic injury: effects of chronic deefferentation and sham surgery. J. Neurophysiol. 78, 3095-3106.

Landsberg, R. L., Awatramani, R. B., Hunter, N. L., Farago, A. F., DiPietrantonio, H. J., Rodriguez, C. I., et al. (2005). Hindbrain rhombic lip is comprised of discrete progenitor cell populations allocated by Pax6. Neuron 48, 933-947. doi: 10.1016/j.neuron.2005.11.031

Lawoko-Kerali, G., Rivolta, M. N., and Holley, M. (2002). Expression of the transcription factors GATA3 and Pax2 during development of the mammalian inner ear. J. Comp. Neurol. 442, 378-391. doi: 10.1002/cne.10088

Lebel, M., Mo, R., Shimamura, K., and Hui, C. C. (2007). Gli2 and Gli3 play distinct roles in the dorsoventral patterning of the mouse hindbrain. Dev. Biol. 302, 345-355. doi: 10.1016/j.ydbio.2006.08.005

Lee, D. J., de Venecia, R. K., Guinan, J. J. Jr., and Brown, M. C. (2006). Central auditory pathways mediating the rat middle ear muscle reflexes. Anat. Rec. A Discov. Mol. Cell. Evol. Biol. 288, 358-369. doi: 10.1002/ar.a.20296

Liberman, M. C., and Guinan, J. J. Jr. (1998). Feedback control of the auditory periphery: anti-masking effects of middle ear muscles vs. olivocochlear efferents. J. Commun. Disord. 31, 471-482; quiz 483; 553. doi: 10.1016/s0021-9924(98)00019-7

Louvi, A., Yoshida, M., and Grove, E. A. (2007). The derivatives of the Wnt3a lineage in the central nervous system. J. Comp. Neurol. 504, 550-569. doi: $10.1002 / \mathrm{cne} .21461$

Lufkin, T., Dierich, A., LeMeur, M., Mark, M., and Chambon, P. (1991). Disruption of the Hox-1.6 homeobox gene results in defects in a region corresponding to its rostral domain of expression. Cell 66, 1105-1119. doi: 10.1016/0092-8674(91)90034-V 
Lumsden, A. (1990). The cellular basis of segmentation in the developing hindbrain. Trends Neurosci. 13, 329-335. doi: 10.1016/0166-2236(90) 90144-Y

Lumsden, A., and Krumlauf, R. (1996). Patterning the vertebrate neuraxis. Science 274, 1109-1115.

Luo, X. J., Deng, M., Xie, X., Huang, L., Wang, H., Jiang, L., et al. (2013). GATA3 controls the specification of prosensory domain and neuronal survival in the mouse cochlea. Hum. Mol. Genet. 22, 3609-3623. doi: 10.1093/hmg/ ddt212

Machold, R., and Fishell, G. (2005). Math1 is expressed in temporally discrete pools of cerebellar rhombic-lip neural progenitors. Neuron 48, 17-24. doi: 10.1016/j.neuron.2005.08.028

Maconochie, M., Nonchev, S., Morrison, A., and Krumlauf, R. (1996). Paralogous Hox genes: function and regulation. Annu. Rev. Genet. 30, 529-556. doi: 10.1146/annurev.genet.30.1.529

Maconochie, M. K., Nonchev, S., Studer, M., Chan, S. K., Popperl, H., Sham, M. H., et al. (1997). Cross-regulation in the mouse HoxB complex: the expression of Hoxb2 in rhombomere 4 is regulated by Hoxb1. Genes Dev. 11, 1885-1895. doi: 10.1101/gad.11.14.1885

Maison, S. F., Luebke, A. E., Liberman, M. C., and Zuo, J. (2002). Efferent protection from acoustic injury is mediated via alpha9 nicotinic acetylcholine receptors on outer hair cells. J. Neurosci. 22, 10838-10846.

Malmierca, M. S., and Merchán, M. A. (2004). "Auditory system," in The Rat Nervous System, 3rd Edn., ed G. Paxinos (San Diego, CA: Academic Press), 997-1082.

Maricich, S. M., Xia, A., Mathes, E. L., Wang, V. Y., Oghalai, J. S., Fritzsch, B., et al. (2009). Atoh1-lineal neurons are required for hearing and for the survival of neurons in the spiral ganglion and brainstem accessory auditory nuclei. J. Neurosci. 29, 11123-11133. doi: 10.1523/JNEUROSCI.223209.2009

Marin, F., Aroca, P., and Puelles, L. (2008). Hox gene colinear expression in the avian medulla oblongata is correlated with pseudorhombomeric domains. Dev. Biol. 323, 230-247. doi: 10.1016/j.ydbio.2008.08.017

Marin, F., and Puelles, L. (1995). Morphological fate of rhombomeres in quail/chick chimeras: a segmental analysis of hindbrain nuclei. Eur. J. Neurosci. 7, 1714-1738. doi: 10.1111/j.1460-9568.1995.tb00693.x

Mark, M., Lufkin, T., Vonesch, J. L., Ruberte, E., Olivo, J. C., Dolle, P., et al. (1993). Two rhombomeres are altered in Hoxa-1 mutant mice. Development 119, 319-338.

Marrs, G. S., Morgan, W. J., Howell, D. M., Spirou, G. A., and Mathers, P. H. (2013). Embryonic origins of the mouse superior olivary complex. Dev. Neurobiol. 73, 384-398. doi: 10.1002/dneu.22069

Marshall, H., Studer, M., Popperl, H., Aparicio, S., Kuroiwa, A., Brenner, S., et al. (1994). A conserved retinoic acid response element required for early expression of the homeobox gene Hoxb-1. Nature 370, 567-571.

Martinez, S. (2001). The isthmic organizer and brain regionalization. Int. J. Dev. Biol. 45, 367-371.

Martinez, S., Geijo, E., Sanchez-Vives, M. V., Puelles, L., and Gallego, R. (1992). Reduced junctional permeability at interrhombomeric boundaries. Development 116, 1069-1076.

Melton, K. R., Iulianella, A., and Trainor, P. A. (2004). Gene expression and regulation of hindbrain and spinal cord development. Front. Biosci. 9:117-138. doi: $10.2741 / 1202$

Muller, T., Brohmann, H., Pierani, A., Heppenstall, P. A., Lewin, G. R., Jessell, T. M., et al. (2002). The homeodomain factor lbxl distinguishes two major programs of neuronal differentiation in the dorsal spinal cord. Neuron 34, 551-562. doi: 10.1016/S0896-6273(02)00689-X

Murphy, P., Davidson, D. R., and Hill, R. E. (1989). Segment-specific expression of a homoeobox-containing gene in the mouse hindbrain. Nature 341, 156-159.

Murphy, P., and Hill, R. E. (1991). Expression of the mouse labial-like homeoboxcontaining genes, Hox 2.9 and Hox 1.6, during segmentation of the hindbrain. Development 111, 61-74.

Nardelli, J., Thiesson, D., Fujiwara, Y., Tsai, F. Y., and Orkin, S. H. (1999). Expression and genetic interaction of transcription factors GATA-2 and GATA3 during development of the mouse central nervous system. Dev. Biol. 210, 305-321. doi: 10.1006/dbio.1999.9278
Narita, Y., and Rijli, F. M. (2009). Hox genes in neural patterning and circuit formation in the mouse hindbrain. Curr. Top. Dev. Biol. 88, 139-167. doi: 10.1016/S0070-2153(09)88005-8

Nichols, D. H., and Bruce, L. L. (2006). Migratory routes and fates of cells transcribing the Wnt-1 gene in the murine hindbrain. Dev. Dyn. 235, 285-300. doi: 10.1002/dvdy.20611

Nonchev, S., Vesque, C., Maconochie, M., Seitanidou, T., Ariza-McNaughton, L., Frain, M., et al. (1996). Segmental expression of Hoxa-2 in the hindbrain is directly regulated by Krox-20. Development $122,543-554$.

Nothwang, H. G. (2016). Evolution of mammalian sound localization circuits: a developmental perspective. Prog. Neurobiol. 141, 1-24. doi: 10.1016/j.pneurobio.2016.02.003

Oertel, D., and Young, E. D. (2004). What's a cerebellar circuit doing in the auditory system? Trends Neurosci. 27, 104-110. doi: 10.1016/j.tins.2003. 12.001

Oury, F., Murakami, Y., Renaud, J. S., Pasqualetti, M., Charnay, P., Ren, S. Y., et al. (2006). Hoxa2- and rhombomere-dependent development of the mouse facial somatosensory map. Science 313, 1408-1413. doi: 10.1126/science.11 30042

Parrish, M., Nolte, C., and Krumlauf, H. (2009). "Hox gene expression," in Developmental Neurobiology, ed G. Lemke (New York, NY: Academic Press), 61-71.

Pascual, M., Abasolo, I., Mingorance-Le Meur, A., Martinez, A., Del Rio, J. A., Wright, C. V., et al. (2007). Cerebellar GABAergic progenitors adopt an external granule cell-like phenotype in the absence of Ptfla transcription factor expression. Proc. Natl. Acad. Sci. U.S.A. 104, 5193-5198. doi: 10.1073/pnas.0605699104

Pasqualetti, M., Diaz, C., Renaud, J. S., Rijli, F. M., and Glover, J. C. (2007). Fate-mapping the mammalian hindbrain: segmental origins of vestibular projection neurons assessed using rhombomere-specific Hoxa2 enhancer elements in the mouse embryo. J. Neurosci. 27, 9670-9681. doi: 10.1523/JNEUROSCI.2189-07.2007

Pata, I., Studer, M., van Doorninck, J. H., Briscoe, J., Kuuse, S., Engel, J. D., et al. (1999). The transcription factor GATA3 is a downstream effector of Hoxb1 specification in rhombomere 4. Development 126, 5523-5531.

Pattyn, A., Hirsch, M., Goridis, C., and Brunet, J. F. (2000). Control of hindbrain motor neuron differentiation by the homeobox gene Phox2b. Development 127, $1349-1358$.

Pattyn, A., Vallstedt, A., Dias, J. M., Sander, M., and Ericson, J. (2003b). Complementary roles for $\mathrm{Nkx} 6$ and $\mathrm{Nkx} 2$ class proteins in the establishment of motoneuron identity in the hindbrain. Development 130, 4149-4159. doi: 10.1242/dev.00641

Pattyn, A., Vallstedt, A., Dias, J. M., Samad, O. A., Krumlauf, R., Rijli, F. M., et al. (2003a). Coordinated temporal and spatial control of motor neuron and serotonergic neuron generation from a common pool of CNS progenitors. Genes Dev. 17, 729-737. doi: 10.1101/gad.255803

Philippidou, P., and Dasen, J. S. (2013). Hox genes: choreographers in neural development, architects of circuit organization. Neuron 80, 12-34. doi: 10.1016/j.neuron.2013.09.020

Popperl, H., Bienz, M., Studer, M., Chan, S. K., Aparicio, S., Brenner, S., et al. (1995). Segmental expression of Hoxb-1 is controlled by a highly conserved autoregulatory loop dependent upon exd/pbx. Cell 81, 1031-1042. doi: $10.1016 /$ S0092-8674(05)80008-X

Prince, V., and Lumsden, A. (1994). Hoxa-2 expression in normal and transposed rhombomeres: independent regulation in the neural tube and neural crest. Development 120, 911-923.

Puelles, L. (2013). "Plan of the developing vertebrate nervous system relating embryology to the adult nervous system (prosomere model, overview of brain organization)," in Comprehensive Developmental Neuroscience: Patterning and Cell Type Specification in the Developing CNS and PNS, eds J. L. R. Rubenstein and P. Rakic (Amsterdam: Academic Press), 187-209.

Puelles, L., Harrison, M., Paxinos, G., and Watson, C. (2013). A developmental ontology for the mammalian brain based on the prosomeric model. Trends Neurosci. 36, 570-578. doi: 10.1016/j.tins.2013.06.004

Quinonez, S. C., and Innis, J. W. (2014). Human HOX gene disorders. Mol. Genet. Metab. 111, 4-15. doi: 10.1016/j.ymgme.2013.10.012

Renier, N., Schonewille, M., Giraudet, F., Badura, A., Tessier-Lavigne, M., Avan, P., et al. (2010). Genetic dissection of the function of hindbrain 
axonal commissures. PLoS Biol. 8:e1000325. doi: 10.1371/journal.pbio.10 00325

Ribes, V., and Briscoe, J. (2009). Establishing and interpreting graded Sonic Hedgehog signaling during vertebrate neural tube patterning: the role of negative feedback. Cold Spring Harb. Perspect. Biol. 1:a002014. doi: 10.1101/cshperspect.a002014

Rijli, F. M., Mark, M., Lakkaraju, S., Dierich, A., Dolle, P., and Chambon, P. (1993). A homeotic transformation is generated in the rostral branchial region of the head by disruption of Hoxa-2, which acts as a selector gene. Cell 75, 1333-1349. doi: 10.1016/0092-8674(93)90620-6

Rose, M. F., Ahmad, K. A., Thaller, C., and Zoghbi, H. Y. (2009). Excitatory neurons of the proprioceptive, interoceptive, and arousal hindbrain networks share a developmental requirement for Math1. Proc. Natl. Acad. Sci. U.S.A. 106, 22462-22467. doi: 10.1073/pnas.0911579106

Samad, O. A., Geisen, M. J., Caronia, G., Varlet, I., Zappavigna, V., Ericson, J., et al. (2004). Integration of anteroposterior and dorsoventral regulation of Phox $2 \mathrm{~b}$ transcription in cranial motoneuron progenitors by homeodomain proteins. Development 131, 4071-4083. doi: 10.1242/dev.01282

Saul, S. M., Brzezinski, J. IV, Altschuler, R. A., Shore, S. E., Rudolph, D. D., Kabara, L. L., et al. (2008). Math5 expression and function in the central auditory system. Mol. Cell. Neurosci. 37, 153-169. doi: 10.1016/j.mcn.2007. 09.006

Sham, M. H., Vesque, C., Nonchev, S., Marshall, H., Frain, M., Gupta, R. D., et al. (1993). The zinc finger gene Krox20 regulates HoxB2 (Hox2.8) during hindbrain segmentation. Cell 72, 183-196. doi: 10.1016/0092-8674(93) 90659-E

Sieber, M. A., Storm, R., Martinez-de-la-Torre, M., Muller, T., Wende, H., Reuter, K., et al. (2007). Lbx1 acts as a selector gene in the fate determination of somatosensory and viscerosensory relay neurons in the hindbrain. J. Neurosci. 27, 4902-4909. doi: 10.1523/JNEUROSCI.071707.2007

Simmons, D. D. (2002). Development of the inner ear efferent system across vertebrate species. J. Neurobiol. 53, 228-250. doi: 10.1002/neu. 10130

Simon, H., and Lumsden, A. (1993). Rhombomere-specific origin of the contralateral vestibulo-acoustic efferent neurons and their migration across the embryonic midline. Neuron 11, 209-220. doi: 10.1016/0896-6273(93) 90179-U

Storm, R., Cholewa-Waclaw, J., Reuter, K., Brohl, D., Sieber, M., Treier, M., et al. (2009). The bHLH transcription factor Olig3 marks the dorsal neuroepithelium of the hindbrain and is essential for the development of brainstem nuclei. Development 136, 295-305. doi: 10.1242/dev.027193

Studer, M., Gavalas, A., Marshall, H., Ariza-McNaughton, L., Rijli, F. M., Chambon, P., et al. (1998). Genetic interactions between Hoxal and Hoxb1 reveal new roles in regulation of early hindbrain patterning. Development 125 , 1025-1036.

Studer, M., Lumsden, A., Ariza-McNaughton, L., Bradley, A., and Krumlauf, R. (1996). Altered segmental identity and abnormal migration of motor neurons in mice lacking Hoxb-1. Nature 384, 630-634.

Studer, M., Popperl, H., Marshall, H., Kuroiwa, A., and Krumlauf, R. (1994). Role of a conserved retinoic acid response element in rhombomere restriction of Hoxb-1. Science 265, 1728-1732.

Szeto, I. Y., Leung, K. K., Sham, M. H., and Cheah, K. S. (2009). Utility of HoxB2 enhancer-mediated Cre activity for functional studies in the developing inner ear. Genesis 47, 361-365. doi: 10.1002/dvg.20507

Takahashi, M., and Osumi, N. (2002). Pax6 regulates specification of ventral neurone subtypes in the hindbrain by establishing progenitor domains. Development 129, 1327-1338.

Tischfield, M. A., Bosley, T. M., Salih, M. A., Alorainy, I. A., Sener, E. C., Nester, M. J., et al. (2005). Homozygous HOXAl mutations disrupt human brainstem, inner ear, cardiovascular and cognitive development. Nat. Genet. 37, 1035-1037. doi: 10.1038/ng1636

Tiveron, M. C., Pattyn, A., Hirsch, M. R., and Brunet, J. F. (2003). Role of Phox2b and Mash1 in the generation of the vestibular efferent nucleus. Dev. Biol. 260, 46-57. doi: 10.1016/S0012-1606(03)00213-6

Tomas-Roca, L., Corral-San-Miguel, R., Aroca, P., Puelles, L., and Marin, F. (2016). Crypto-rhombomeres of the mouse medulla oblongata, defined by molecular and morphological features. Brain Struct. Funct. 221, 815-838. doi: 10.1007/s00429-014-0938-y

Tumpel, S., Cambronero, F., Ferretti, E., Blasi, F., Wiedemann, L. M., and Krumlauf, R. (2007). Expression of Hoxa2 in rhombomere 4 is regulated by a conserved cross-regulatory mechanism dependent upon Hoxb1. Dev. Biol. 302, 646-660. doi: 10.1016/j.ydbio.2006.10.029

Tumpel, S., Wiedemann, L. M., and Krumlauf, R. (2009). Hox genes and segmentation of the vertebrate hindbrain. Curr. Top. Dev. Biol. 88, 103-137. doi: 10.1016/S0070-2153(09)88004-6

Ulloa, F., and Marti, E. (2010). Wnt won the war: antagonistic role of Wnt over Shh controls dorso-ventral patterning of the vertebrate neural tube. Dev. Dyn. 239, 69-76. doi: 10.1002/dvdy.22058

Vaage, S. (1969). The segmentation of the primitive neural tube in chick embryos (Gallus domesticus). A morphological, histochemical and autoradiographical investigation. Ergeb. Anat. Entwicklungsgesch. 41, $3-87$.

van der Wees, J., van Looij, M. A., de Ruiter, M. M., Elias, H., van der Burg, H., Liem, S. S., et al. (2004). Hearing loss following Gata3 haploinsufficiency is caused by cochlear disorder. Neurobiol. Dis. 16, 169-178. doi: 10.1016/j.nbd.2004.02.004

Van Esch, H., Groenen, P., Nesbit, M. A., Schuffenhauer, S., Lichtner, P., Vanderlinden, G., et al. (2000). GATA3 haplo-insufficiency causes human HDR syndrome. Nature 406, 419-422. doi: 10.1038/350 19088

van Looij, M. A., van der Burg, H., van der Giessen, R. S., de Ruiter, M. M., van der Wees, J., van Doorninck, J. H., et al. (2005). GATA3 haploinsufficiency causes a rapid deterioration of distortion product otoacoustic emissions (DPOAEs) in mice. Neurobiol. Dis. 20, 890-897. doi: 10.1016/j.nbd.2005. 05.025

Vetter, D. E., Katz, E., Maison, S. F., Taranda, J., Turcan, S., Ballestero, J., et al. (2007). The alpha10 nicotinic acetylcholine receptor subunit is required for normal synaptic function and integrity of the olivocochlear system. Proc. Natl. Acad. Sci. U.S.A. 104, 20594-20599. doi: 10.1073/pnas.07085 45105

Vetter, D. E., Liberman, M. C., Mann, J., Barhanin, J., Boulter, J., Brown, M. C., et al. (1999). Role of alpha9 nicotinic ACh receptor subunits in the development and function of cochlear efferent innervation. Neuron 23, 93-103. doi: 10.1016/S0896-6273(00)80756-4

Voiculescu, O., Charnay, P., and Schneider-Maunoury, S. (2000). Expression pattern of a Krox-20/Cre knock-in allele in the developing hindbrain, bones, and peripheral nervous system. Genesis 26, 123-126. doi: 10.1002/(SICI)1526-968X(200002)26:2<123::AID-GENE7>3.0.CO;2-O

Walsh, E. J., McGee, J., McFadden, S. L., and Liberman, M. C. (1998). Long-term effects of sectioning the olivocochlear bundle in neonatal cats. J. Neurosci. 18, 3859-3869.

Wang, V. Y., Rose, M. F., and Zoghbi, H. Y. (2005). Math1 expression redefines the rhombic lip derivatives and reveals novel lineages within the brainstem and cerebellum. Neuron 48, 31-43. doi: 10.1016/j.neuron.2005. 08.024

Webb, B. D., Shaaban, S., Gaspar, H., Cunha, L. F., Schubert, C. R., Hao, K., et al. (2012). HOXB1 founder mutation in humans recapitulates the phenotype of Hoxb1-/- mice. Am. J. Hum. Genet. 91, 171-179. doi: 10.1016/j.ajhg.2012.05.018

Wersinger, E., and Fuchs, P. A. (2011). Modulation of hair cell efferents. Hear. Res. 279, 1-12. doi: 10.1016/j.heares.2010.12.018

Wilkinson, D. G., Bhatt, S., Cook, M., Boncinelli, E., and Krumlauf, R. (1989). Segmental expression of Hox-2 homoeobox-containing genes in the developing mouse hindbrain. Nature 341, 405-409.

Willaredt, M. A., Ebbers, L., and Nothwang, H. G. (2014). Central auditory function of deafness genes. Hear. Res. 312, 9-20. doi: 10.1016/j.heares.2014.02.004

Willott, J. F. (2001). Handbook of Mouse Auditory Research from Behavior to Molecular Biology. Boca Raton, FL: CRC.

Wingate, R. J., and Lumsden, A. (1996). Persistence of rhombomeric organisation in the postsegmental hindbrain. Development 122, 2143-2152.

Yamada, M., Seto, Y., Taya, S., Owa, T., Inoue, Y. U., Inoue, T., et al. (2014). Specification of spatial identities of cerebellar neuron progenitors by ptfla 
and atoh1 for proper production of GABAergic and glutamatergic neurons. $J$. Neurosci. 34, 4786-4800. doi: 10.1523/JNEUROSCI.2722-13.2014

Yamada, M., Terao, M., Terashima, T., Fujiyama, T., Kawaguchi, Y., Nabeshima, Y., et al. (2007). Origin of climbing fiber neurons and their developmental dependence on Ptf1a. J. Neurosci. 27, 10924-10934. doi: 10.1523/JNEUROSCI.1423-07.2007

Zhang, H., and Kelly, J. B. (2006). Responses of neurons in the rat's ventral nucleus of the lateral lemniscus to amplitudemodulated tones. J. Neurophysiol. 96, 2905-2914. doi: 10.1152/jn.004 81.2006
Conflict of Interest Statement: The authors declare that the research was conducted in the absence of any commercial or financial relationships that could be construed as a potential conflict of interest.

Copyright (c) 2017 Di Bonito and Studer. This is an open-access article distributed under the terms of the Creative Commons Attribution License (CC BY). The use, distribution or reproduction in other forums is permitted, provided the original author(s) or licensor are credited and that the original publication in this journal is cited, in accordance with accepted academic practice. No use, distribution or reproduction is permitted which does not comply with these terms. 